\title{
Oxidative stress profiles in brain point out a higher susceptibility of fish to waterborne divalent mercury compared to dietary organic mercury
}

\author{
Olívia Cardoso $^{\mathrm{a}}$, Sónia Puga ${ }^{\mathrm{b}, \mathrm{c}}$, Fátima Brandão ${ }^{\mathrm{d}, \mathrm{e}}$, João Canário ${ }^{\mathrm{f}}$, Nelson J. O'Driscoll ${ }^{\mathrm{g}}$, \\ Maria Ana Santos ${ }^{\mathrm{a}}$, Mário Pacheco ${ }^{\mathrm{a}}$, Patrícia Pereira ${ }^{\mathrm{a}, *}$

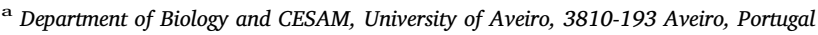 \\ b Life and Health Sciences Research Institute (ICVS), School of Medicine (EM), Campus of Gualtar, University of Minho, 4750-057 Braga, Portugal \\ c ICVS/3B's - PT Government Associate Laboratory, Braga/Guimarães, Portugal \\ d Department of Environmental Health, Portuguese National Institute of Health, Porto, Portugal \\ e ISPUP-EPI Unit, Universidade do Porto, Rua das Taipas, no. 135, 4050-600 Porto, Portugal \\ ${ }^{\mathrm{f}}$ Centro de Química Estrutural, Instituto Superior Técnico, Universidade de Lisboa, Av. Rovisco Pais, 1049-001 Lisboa, Portugal \\ ${ }^{g}$ Department of Earth and Environmental Science, Center for Analytical Research on the Environment, K.C. Irving Center, Acadia University, Wolfville, Nova Scotia, \\ Canada.
}

\section{A R T I C L E I N F O}

\section{Keywords:}

Inorganic mercury

Methylmercury

Neurotoxicity

Oxidative stress

Brain

Fish

\begin{abstract}
A B S T R A C T
This study examines, for the first time, the neurotoxicity of $\mathrm{Hg}$ (II) and $\mathrm{MeHg}$ in fish (Diplodus sargus) in a timecourse comparative perspective and considering realistic exposure levels and routes. Both forms followed an identical time-variation pattern of accumulation in the brain, but dietary $\mathrm{MeHg}$ was more efficiently transported to the brain. $\mathrm{MeHg}$ was substantially eliminated from the brain in 28 days of depuration, which did not occur for $\mathrm{Hg}$ (II). Moreover, $\mathrm{Hg}$ (II) displayed a high neurotoxicity potential, as unveiled by the poor activation of brain antioxidant defenses and recurrent oxidative damage (as protein oxidation), while the opposite was recorded upon $\mathrm{MeHg}$ exposure. These results highlight the need to include $\mathrm{Hg}$ (II) in future environmental health assessment plans, preventing an underestimation of the risk for wild fish populations, which has probably been occurring due to the long-standing idea of the higher toxicity of $\mathrm{MeHg}$ in comparison with inorganic $\mathrm{Hg}$ forms.
\end{abstract}

\section{Introduction}

Mercury (Hg) has triggered major environmental and human health concerns. This element is present in aquatic environments in organic (primarily methylmercury - $\mathrm{MeHg}$ ) and inorganic forms [e.g. $\mathrm{Hg}$ (II) and $\mathrm{Hg}(0)$ ], and both can be bioaccumulated by fish, exerting toxicity at different biological levels. Some of the reported $\mathrm{Hg}$ effects in fish are inhibition of hepatic biotransformation enzymes (Guilherme et al., 2008a), oxidative stress in the brain (Berntssen et al., 2003), genotoxicity in blood (Guilherme et al., 2008b) and reproductive alterations (Crump and Trudeau, 2009). However, there are fundamental knowledge gaps concerning the effects of mercury species on the fish brain. This is an important issue since fish fitness and survival are significantly affected by the neurotoxic effects of $\mathrm{Hg}$ exposure (Farina et al., 2013; Pereira et al., 2016; Puga et al., 2016).

While there are a few studies on the neurotoxicity of $\mathrm{MeHg}$ in fish (Berntssen et al., 2003; Puga et al., 2016), there is very little information on the ability of divalent mercury [Hg(II)] to accumulate in fish brain and the resulting effects. The primary focus on MeHg in the literature is likely due to the perception of its higher toxicity associated with rapid uptake and partitioning to sensitive tissues such as the brain. However, some research has indicated that $\mathrm{Hg}$ (II) can also easily cross the blood-brain barrier (BBB) and result in neurotoxicity (Aschner and Aschner, 2007; Farina et al., 2013). In contrast to those works, Rouleau et al. (1999) postulated that the BBB is relatively impervious to $\mathrm{Hg}(\mathrm{II})$. However, $\mathrm{HgCl}_{2}$ can act as a direct $\mathrm{BBB}$ toxicant in rodents, thus increasing its permeability (Zheng et al., 2003). Our previous work has shown that $\mathrm{Hg}(\mathrm{II})$ can reach fish brain after only three days of exposure to environmentally realistic levels in water (Pereira et al., 2015), resulting in a reduction in the number of cells in specific brain areas, as well as impairing swimming behavior (Pereira et al., 2016). This is in line with other studies that have documented the occurrence of inorganic forms of $\mathrm{Hg}$ in fish brain (Berntssen et al., 2003; Korbas et al., 2012; Wang et al., 2015). It has been also hypothesized that the different forms of $\mathrm{Hg}$ share the same toxic chemical entity and, thus, neurotoxicity depends mainly on the external bioavailability (De Flora et al., 1994). In fact, $\mathrm{HgCl}_{2}$ displayed higher toxicity than $\mathrm{MeHg}$ in glial cells and neurons of immature aggregate cultures of rat telencephalon

\footnotetext{
* Corresponding author.

E-mail address: pkpereira@ua.pt (P. Pereira).
} 
(Monnet-Tschudi et al., 1996). Within a different framework, Clarkson and Magos (2006) postulated that the conversion of inorganic $\mathrm{Hg}$ into $\mathrm{MeHg}$ by microorganisms in aquatic sediments could be a protective mechanism since $\mathrm{Hg}(\mathrm{II})$ is more toxic. In light of this controversy, more research is needed to evaluate and compare the neurotoxic mechanisms of $\mathrm{Hg}$ (II) and $\mathrm{MeHg}$ exposure in fish.

It is well established that oxidative stress, emerging from the imbalance between the production and removal of reactive oxidative species (ROS) (Ercal et al., 2001), is a key pathway to trigger Hg neurotoxicity in mammals (Aschner and Aschner, 2007; Farina et al., 2013). Mercury is highly reactive with sulfhydryl groups, forming covalent bonds with GSH and cysteine residues of proteins. In particular, GSH directly binds to $\mathrm{MeHg}$ acting as an endogenous ligand, and the complex formed contributes to MeHg efflux from the cells (Clarkson and Magos, 2006). In the same direction, it has been foreseen that $\mathrm{MeHg}$ promotes a decrease in intracellular GSH levels, which is considered one of its cytotoxic effects (Choi et al., 1996). Additionally, the inhibition of antioxidant enzymes has been referred as a relevant mechanism involved in oxidative stress due to $\mathrm{Hg}$ (Roos et al., 2009). Only a few studies had searched for the modulation of antioxidant enzymes and alterations in GSH content in fish brain after $\mathrm{Hg}$ exposure (Berntssen et al., 2003; Mieiro et al., 2011). Moreover, most of those studies were performed under field conditions where a simultaneous exposure of fish to $\mathrm{Hg}(\mathrm{II})$ and $\mathrm{MeHg}$ occurs, hindering conclusions about the neurotoxicity potential of each $\mathrm{Hg}$ counterpart. Additionally, laboratory exposures generally considered a single $\mathrm{Hg}$ species, not comparing organic and inorganic forms. So, there is still a lack of studies elucidating the modulation of the antioxidant system and subsequent emergence of oxidative damage in fish brain after exposure to $\mathrm{Hg}$ (II) and MeHg. Nevertheless, Berntssen et al. (2003) found a significant increase of lipid peroxidative products after dietary exposure to $\mathrm{MeHg}$ together with a decrease of antioxidant enzymes activity (superoxide dismutase - SOD; glutathione peroxidase - GPx), while no significant changes of those endpoints were observed upon exposure to inorganic $\mathrm{Hg}$ in food. Despite these contributions, Berntssen et al. (2003) did not assessed the time-evolution of $\mathrm{Hg}$ accumulation/depuration and oxidative stress responses, as well as the potential reversibility of toxicity events.

In order to examine these gaps in research, the present study compares the neurotoxic effects of $\mathrm{Hg}$ (II) and $\mathrm{MeHg}$ exposure on brain of fish (white seabream - Diplodus sargus) by the combination of bioaccumulation levels and oxidative stress profiles in a time-course experiment, incorporating both exposure and post-exposure periods. In order to do this, two separate experiments were performed with comparable daily exposure levels of both $\mathrm{Hg}$ forms. Realistic exposure levels and routes were tested, viz. waterborne exposure to $\mathrm{Hg}$ (II) $\left(2 \mu \mathrm{g} \mathrm{L}^{-1}\right)$ and dietary exposure to $\mathrm{MeHg}\left(8.7 \mu \mathrm{g} \mathrm{g}^{-1}\right.$ feed dry weight). Ultimately, it was intended to clarify the toxicokinetics and toxicodynamics of both $\mathrm{Hg}$ forms, providing reliable data to environmental health assessment.

\section{Material and methods}

\subsection{Experimental set-up}

Two experiments, with the same design (Fig. 1), were performed with juvenile white seabreams (Diplodus sargus) provided by an Aquaculture Research Station (IPMA - Olhão, Portugal), under a 14:10 light:dark photoperiod. Fish were held in $300 \mathrm{~L}$ fiberglass tanks in an average density of $0.062 \mathrm{~kg} \mathrm{~L}^{-1}$ in the $\mathrm{Hg}$ (II) experiment (fish weight: $146 \pm 14 \mathrm{~g}$; total length: $19 \pm 1 \mathrm{~cm}$ ) and $0.056 \mathrm{~kg} \mathrm{~L}^{-1}$ in the $\mathrm{MeHg}$ experiment (fish weight: $124 \pm 11 \mathrm{~g}$; total length: $18 \pm 0.6 \mathrm{~cm}$ ). Fish were exposed to $\mathrm{Hg}$ (II) via water $\left(\mathrm{HgCl}_{2}\right)$, while $\mathrm{MeHg}\left(\mathrm{CH}_{3} \mathrm{HgCl}\right)$ was provided to fish through contaminated pellets. In both experiments, seawater was renewed daily $(\sim 80 \%$ renewal) and fish were fed once a day, namely $1-2 \mathrm{~h}$ before water renewal. In all sampling days, fish were not fed in the $12 \mathrm{~h}$ preceding fish handling. Water temperature, salinity and $\mathrm{pH}$ were monitored daily throughout the $\mathrm{Hg}(\mathrm{II})$ and $\mathrm{MeHg}$ experiments, varying as follows, respectively: $14 \pm 0.3{ }^{\circ} \mathrm{C}$ and $17 \pm 2.0^{\circ} \mathrm{C}$ (mean \pm standard deviation); $35 \pm 2$ and $35 \pm 1$ psu (mean \pm standard deviation); 7.4-7.9 and 7.6-7.9 (range).

In the $\mathrm{Hg}$ (II) experiment, $\mathrm{HgCl}_{2}$ (Sigma-Aldrich) was added to the water of exposure tanks in an aqueous solution in order to reach an initial nominal concentration of $2 \mu \mathrm{g} \mathrm{L}{ }^{-1}$. Divalent mercury was added on a daily basis after water renewal (i.e. daily water recontamination) during the exposure period. Exposure level of $\mathrm{Hg}$ (II) was established considering previous studies in contaminated areas (Horvat et al., 2003; Li et al., 2009), in order to mimic environmentally realistic conditions. Fish were exposed to $\mathrm{Hg}$ (II) in the current work since it is believed to be the proximate toxic agent for several inorganic forms of mercury (Clarkson and Magos, 2006). Control fish were kept throughout the experiment in tanks filled with clean seawater. In this experiment, fish were fed with a commercial dry food [standard $3 \mathrm{~mm}$ from Sorgal (Portugal)] with vestigial $\mathrm{Hg}$ levels (lower than $0.01 \mu \mathrm{g} \mathrm{g}^{-1}$ ).

In the MeHg experiment, MeHg-contaminated pellets $\left(8.7 \mu \mathrm{g} \mathrm{g}^{-1}\right.$ dry weight) were used to feed exposed fish. This MeHg exposure level is also environmentally realistic since natural food of $D$. sargus (e.g. Nereis diversicolor) from contaminated areas can have such high levels of $\mathrm{MeHg}$ (Pereira et al., unpublished data), which is also in agreement with levels found in benthic species from $\mathrm{Hg}$ contaminated areas (Locarnini and Presley, 1996). Contaminated feed (3 mm pellets) was produced by SPAROS company (Portugal) using a solution of $\mathrm{MeHg}$ chloride $\left(\mathrm{CH}_{3} \mathrm{HgCl}\right.$; Sigma-Aldrich; prepared in ethanol) that was added during the process of pellet production, with a homogenous distribution of toxicant throughout the batch. Fish were feed at a daily feeding rate of $3 \%$ (as percentage of fish biomass, corresponding to $30 \mathrm{~g}$ food/day/ $\mathrm{kg}$ of fish). Control fish were fed with food prepared in the same occasion but without adding $\mathrm{MeHg}$ (intrinsic $\mathrm{MeHg}$ levels lower than $0.01 \mu \mathrm{g} \mathrm{g}^{-1}$ ).

As a premise to allow the comparison of the neurotoxic potential of both $\mathrm{Hg}$ forms, comparable daily exposure levels were sought in both experiments, which were translated in the values of 265 and $261 \mu \mathrm{g} /$ day $/ \mathrm{kg}$ of body weight, respectively for $\mathrm{Hg}(\mathrm{II})$ and $\mathrm{MeHg}$. Daily exposure values were estimated considering the amount of food ingested and the corresponding mass of metal vehiculated for $\mathrm{MeHg}$ experiment, while for $\mathrm{Hg}(\mathrm{II})$ experiment it was considered that the difference between the initial nominal concentration and the concentration measured before recontamination (maximum value corresponding to $18 \%$ of the initial concentration) represents a rough measure of the $\mathrm{Hg}$ that was taken up, assuming negligible losses by volatilization and adsorption to tank surface (plausible due to daily recontamination) in line with previous findings (Oliveira Ribeiro et al., 2000).

In both experiments, fish were allowed to acclimatize to experimental conditions and routines for two weeks prior to $\mathrm{Hg}$ exposure. Fish were exposed to $\mathrm{Hg}$ (II) or MeHg for 1 (E1), 3 (E3), 7 (E7) and 14 (E14) days (Fig. 1). Thereafter, fish were transferred to clean water (postexposure in $\mathrm{Hg}$ (II) experiment) or feed shifted to uncontaminated pellets (post-exposure in $\mathrm{MeHg}$ experiment) and allowed to recover for 14 (PE14) and 28 days (PE28). At each sampling time, 8 fish were sampled per condition $(n=8)$ and the brain was divided longitudinally in two sets, one for $\mathrm{Hg}$ quantification and the other for determination of oxidative stress related endpoints. Experiments had a total duration of 42 days and fish wellbeing deserved a permanent attention along that time, in accordance with national and international guidelines for the protection of animal welfare.

During the exposure period (at days 1, 3, 7 and 14) of $\mathrm{Hg}(\mathrm{II})$ experiment, water samples were collected in triplicate, $24 \mathrm{~h}$ after recontamination, to quantify total $\mathrm{Hg}(\mathrm{tHg})$ levels, in order to assess the toxicant bioavailability. Values of $\mathrm{tHg}$ in the exposure tanks immediately before recontamination varied between 0.05 and $0.36 \mu \mathrm{g} \mathrm{L}-1$, which would correspond to the minimum exposure concentration. Levels of $\mathrm{tHg}$ in the control tanks were below the detection limit $\left(0.1 \mathrm{ng} \mathrm{L}^{-1}\right)$ throughout the experiment, as well as at days 28 and 

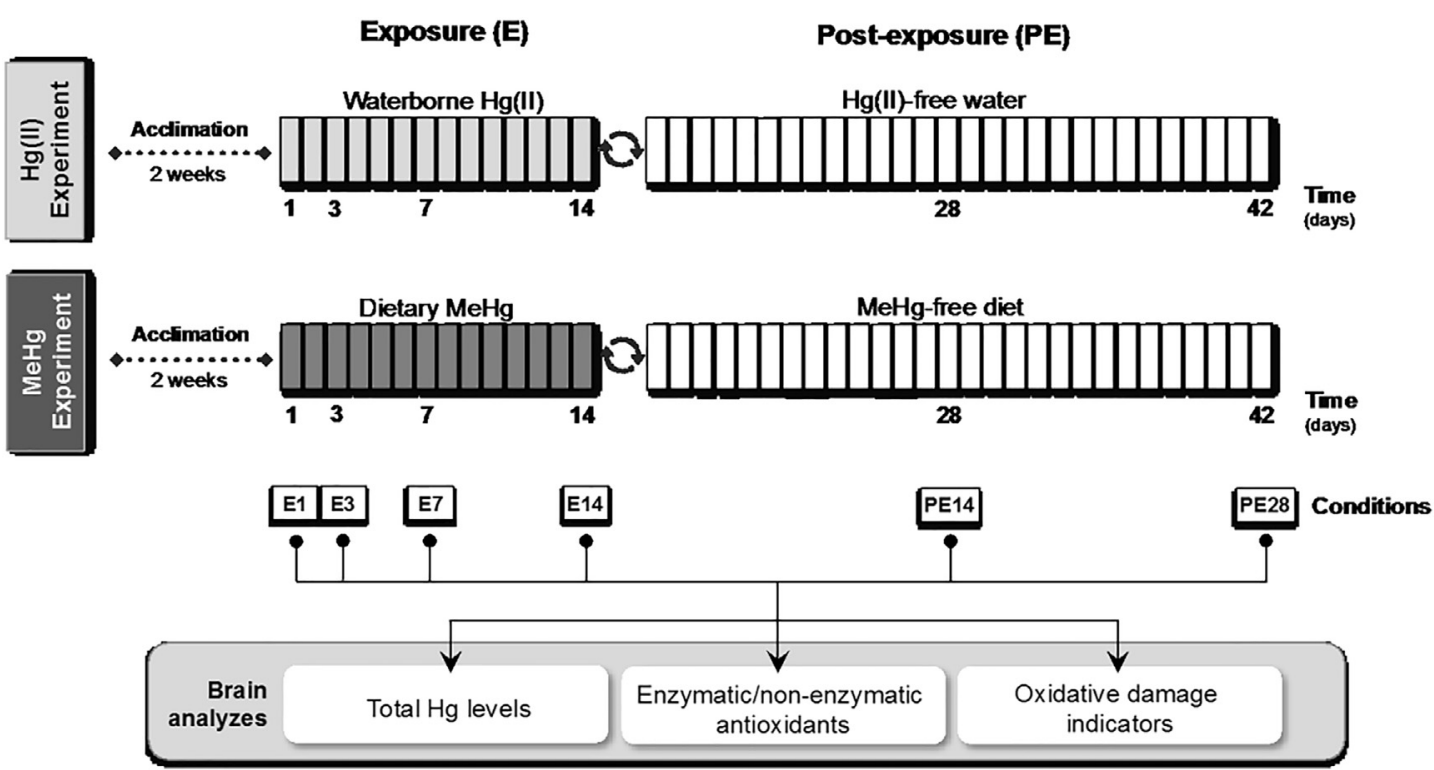

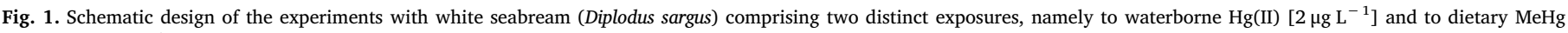

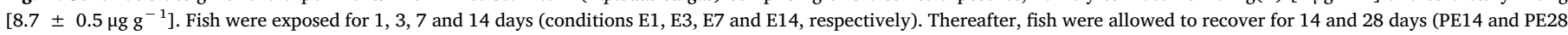
condition) under mercury-free conditions. In parallel, control groups were also considered.

42 (post-exposure period) in control and in previously contaminated tanks. Water samples were also taken along with $\mathrm{MeHg}$ exposure and tHg levels in the water were below the analytical detection limit.

The fish condition was assessed along both experiments through the Fulton's condition factor (K), according to the expression $\mathrm{K}=$ $(\mathrm{W} \times 100) / \mathrm{L}^{3}$, where $\mathrm{W}=$ weight $(\mathrm{g})$ and $\mathrm{L}=$ total length $(\mathrm{cm})$.

\subsection{Brain collection}

Immediately after collection, fish were anesthetized with tricaine methanesulfonate (MS-222), weighed, measured, and sacrificed by cervical transection. Then, fish were bled (with heparinized Pasteur pipettes at the cardinal vein) and brain was removed and stored at $-80^{\circ} \mathrm{C}$ until further processing for tHg determination and evaluation of oxidative stress related endpoints.

\subsection{Mercury analyses in brain}

Brain samples were first lyophilized, homogenized and then analyzed for total $\mathrm{Hg}$ ( $\mathrm{tHg}$ ) in an Advanced Mercury Analyzer (AMA) (AMA254, LECO Instruments) according to the EPA method 7473 (EPA, 1998). Briefly, the initial preparation step in the analytical process of AMA was removing the moisture through a drying process to concentrate $\mathrm{Hg}$ in the sample. Thermal decomposition (around $750{ }^{\circ} \mathrm{C}$ ) was used to pyrolytically reduce $\mathrm{Hg}$ in the sample to its elemental form. Elemental $\mathrm{Hg}$ was then trapped on a gold amalgamator and eventually liberated by heating the amalgamator. Elemental $\mathrm{Hg}$ was transported by a stream of oxygen and measured by atomic absorption spectrometry (Costley et al., 2000). Certified reference materials (fish protein DORM-4; dogfish liver - DOLT-4) from the Canadian National Research Council were used to ensure the accuracy of the procedure and the obtained values were consistent with the certified ones. Total mercury (tHg) levels in brain samples from the $\mathrm{Hg}$ (II) experiment allowed toxicokinetics interpretations based on the assumption that fish were exposed to $\mathrm{Hg}$ (II) and that no methylation occurred (Pereira et al., 2015). Similarly, tHg levels in the brain allowed interpretations on $\mathrm{MeHg}$ toxicokinetics upon exposure to this form since $\mathrm{Hg}$ (II) levels were already determined in those brain samples and its occurrence was lower than $1.5 \%$ of tHg (Puga et al., 2016).

\subsection{Analyses of antioxidants and oxidative damage in the brain}

Tissue samples were homogenized in a 1:8 ratio (brain weight:buffer volume) of chilled phosphate buffer $(0.1 \mathrm{M}, \mathrm{pH} 7.4)$ using a Potter-Elvehjem homogenizer. The homogenate was divided in two aliquots, one for lipid peroxidation (LPO) evaluation and another for post-microsomal supernatant (PMS) preparation. The aliquot for LPO evaluation was stored with 1:10 butylated hydroxytoluene (prepared in $4 \%$ of methanol) and phosphate buffer. The PMS fraction, obtained by centrifugation in a refrigerated centrifuge (Eppendorf 5415R) at $13,400 \mathrm{~g}$ for $25 \mathrm{~min}$ at $4{ }^{\circ} \mathrm{C}$, was divided in aliquots to be used for different antioxidant determinations. All the aliquots were stored at $-80{ }^{\circ} \mathrm{C}$ until spectrophotometric analyses in a SpectraMax $190 \mathrm{mi}-$ croplate reader (at $25^{\circ} \mathrm{C}$ ), which consisted on the following procedures:

- Superoxide dismutase (SOD) activity was measured in PMS using a spectrophotometric enzymatic kit (RANSOD TM, Randox) according to the manufacturers' instructions, and adapted to microplate. This methodology employs xanthine and xanthine oxidase to generate superoxide radicals that react with 2-(4-iodophenyl)-3-(4-nitrophenol)-5-phenyltetrazolium chloride (INT) to form a red formazan dye. Changes in absorbance were recorded in $30 \mathrm{~s}$ cycles for $3 \mathrm{~min}$ at $505 \mathrm{~nm}$. SOD activity is then measured by the degree of inhibition of this reaction. One unit of SOD is the amount that causes a $50 \%$ inhibition of the rate of reduction of INT, under the conditions of the assay. Results were expressed as SOD units per mg of protein;

- Catalase (CAT) activity was measured in PMS by Claiborne (1985) method as described by Giri et al. (1996). Briefly, the assay mixture consisted $185 \mu \mathrm{L}$ hydrogen peroxide $(10 \mathrm{mM})$ and $15 \mu \mathrm{L}$ of sample in final volume of $200 \mu \mathrm{L}$. Change in absorbance was recorded at $240 \mathrm{~nm}$ and CAT activity was expressed in terms of $\mu \mathrm{mol} \mathrm{H}_{2} \mathrm{O}_{2}$ consumed per min per mg of protein, using a molar extinction coefficient $(\varepsilon)$ of $43.5 \mathrm{M}^{-1} \mathrm{~cm}^{-1}$;

- Glutathione peroxidase (GPx) activity was determined in PMS according to the method described by Flohé and Günzler (1984), adapted to 96 -well microplate. The assay mixture consisted of $90 \mu \mathrm{L}$ phosphate buffer (0.05 M, pH 7.0), $30 \mu \mathrm{L}$ of PMS (diluted properly), $30 \mu \mathrm{L}$ GR $\left(2.4 \mathrm{IU} \mathrm{mL}^{-1}\right), 30 \mu \mathrm{L}$ reduced glutathione (GSH; $10 \mathrm{mM}$ ), $30 \mu \mathrm{L}$ sodium azide $(10 \mathrm{mM}), 30 \mu \mathrm{L}$ EDTA $(10 \mathrm{mM}), 30 \mu \mathrm{L} \mathrm{NADPH}$ 
(1.5 mM) and $30 \mu \mathrm{L} \mathrm{H}_{2} \mathrm{O}_{2}(2.5 \mathrm{mM})$ and in a total volume of $300 \mu \mathrm{L}$. GPx activity was determined by monitoring the oxidation of NADPH to NADP +, resulting in an absorbance decrease at $340 \mathrm{~nm}$. The absorbance was read every $30 \mathrm{~s}$ for a period of $5 \mathrm{~min}$. GPx activity was calculated in terms of nmol NADPH oxidized per min per mg of protein, using a $\varepsilon$ of $6.22 \mathrm{mM}^{-1} \mathrm{~cm}^{-1}$;

- Glutathione reductase (GR) activity was assayed by the method of Cribb et al. (1989) adapted to 96-well microplate. Briefly, the assay mixture contained $50 \mu \mathrm{L}$ of PMS fraction and $250 \mu \mathrm{L}$ of NADPH (0.206 mM), glutathione disulfide (GSSG - $1.068 \mathrm{mM}$ ) and diethylene triaminepentaacetic acid (DTPA - $0.549 \mathrm{mM}$ ). The enzyme activity was quantified by measuring the disappearance of NADPH at $340 \mathrm{~nm}$ during $5 \mathrm{~min}$. The enzyme activity was calculated as nmol NADPH oxidized per min per $\mathrm{mg}$ of protein, using a $\varepsilon$ of $6.22 \mathrm{mM}^{-1} \mathrm{~cm}^{-1}$;

- Glutathione-S-transferase (GST) activity was determined according to the method of Habig et al. (1974) using CDNB (1-chloro-2,4-dinitrobenzene) as substrate. The assay was carried out in a 96-well microplate with a $100 \mu \mathrm{L}$ of PMS (diluted properly) and $175 \mu \mathrm{L}$ of GSH (1.765 mM; prepared in phosphate buffer $0.2 \mathrm{M}$, pH 7.9). The reaction was initiated by addition of $30 \mu \mathrm{L}$ of 1-chloro-2,4-dinitrobenzene (CDNB; $10 \mathrm{mM}$ ), and the increase in absorbance was recorded spectrophotometrically at $340 \mathrm{~nm}$, during 5 min each $30 \mathrm{~s}$. GST activity was expressed as nmol of thioesther produced per min per $\mathrm{mg}$ of protein, using a $\varepsilon$ of $9.6 \mathrm{mM}^{-1} \mathrm{~cm}^{-1}$.

- Total glutathione (tGSH) content was measured following the method of Baker et al. (1990) adapted to a microplate reader by Vandeputte et al. (1994). Protein content in the PMS was precipitated with trichloroacetic acid (TCA 12\%) for $1 \mathrm{~h}$ and then centrifuged at $12,000 \mathrm{~g}$ for $5 \mathrm{~min}$ at $4{ }^{\circ} \mathrm{C}$. tGSH was determined (in deproteinated PMS) adopting the enzymatic recycling method using GR excess, whereby the sulfhydryl group of GSH reacts with DTNB (5,5'-dithiobis-2-nitrobenzoic acid, Ellman's reagent) producing a yellow coloured 5-thio-2-nitrobenzoicacid (TNB). Reaction mixture containing $1 \mathrm{mM}$ DTNB, $0.34 \mathrm{mM}$ NADPH dissolved in a stock sodium phosphate buffer (143 mM with $6.3 \mathrm{mM}$ EDTA, pH 7.4) was added to wells containing $40 \mu \mathrm{L}$ of deproteinated PMS (previously diluted 1:3) and the reaction was started by adding $40 \mu \mathrm{L}$ of $8.5 \mathrm{IU} \mathrm{mL}^{-1} \mathrm{GR}$. Formation of TNB was monitored by spectrophotometry at $415 \mathrm{~nm}$ for $7 \mathrm{~min}$. The results were expressed as nmol TNB conjugated per min per $\mathrm{mg}$ of protein, using a $\varepsilon$ of $14.1 \mathrm{mM}^{-1} \mathrm{~cm}^{-1}$.

- LPO was determined in the previously prepared homogenate as adapted by Filho et al. (2001) after Bird and Draper (1984). Briefly, $250 \mu \mathrm{L}$ of TCA (12\%) in aqueous solution, $225 \mu \mathrm{L}$ of Tris- $\mathrm{HCl}$ ( $60 \mathrm{mM}$, pH 7.4, and $0.1 \mathrm{mM}$ DTPA) and $250 \mu \mathrm{L}$ of TBA $(0.73 \%)$ were added and thoroughly mixed with $150 \mu \mathrm{L}$ of the homogenate. This mixture was heated for $1 \mathrm{~h}$ in a water bath set at boiling temperature and then cooled to room temperature, decanted into $1.5 \mathrm{~mL}$ microtubes and centrifuged at $15,800 \mathrm{~g}$ for $5 \mathrm{~min}$. Absorbance was measured at $535 \mathrm{~nm}$, and LPO was expressed as nanomoles of thiobarbituric acid reactive substances (TBARS) formed per $\mathrm{mg}$ of protein, using a $\varepsilon$ of $1.56 \times 105 \mathrm{M}^{-1} \mathrm{~cm}^{-1}$.

- Carbonyl groups were determined as a measure of protein oxidation, using a commercial kit (Protein Carbonyl Content Assay Kit - Ref MAK094, Sigma Aldrich), according to manufacturer's instructions with some modifications, namely an additional rinse of the pellet with acetone and an additional centrifugation at the final of assay before the reading. The carbonyl content was determined by the derivatization of protein carbonyl groups with 2,4-dinitrophenylhydrazine (DNPH), leading to the formation of stable dinitrophenyl (DNP) hydrazone adducts, which can be detected spectrophotometrically at $375 \mathrm{~nm}$. Values were expressed as nanomoles of DNP hydrazone adducts formed per mg of protein, using a $\varepsilon$ of $22 \mathrm{mM}^{-1} \mathrm{~cm}^{-1}$.
Protein concentrations of PMS and homogenates were determined (at $550 \mathrm{~nm}$ ) according to the Biuret method (Gornall et al., 1949), adapted to microplate, in order to express enzymatic activities, tGSH and TBARS as a function of protein content. In turn, protein concentration of samples in the carbonyl groups assay was determined at $562 \mathrm{~nm}$, using the BCA (Bicinchoninic Acid Kit) Assay Kit (Ref - BCA1 AND B9643) according to the manufacturer's instructions. In both methods, bovine serum albumin was used as standard.

\subsection{Data analysis}

The statistical analyses were performed with GraphPad Prism v6.01 (Windows). The distribution of the variables was considered to be normal if the absolute skew value was less than 2 and the absolute kurtosis less than 7 (West et al., 1995). As all dependent variables fell within these cut-off values, Student's $t$-tests (unpaired, two-tailed) were used throughout this study to compare control and exposed fish in each time-point. Identically, a comparison of mean values at different timepoints was performed within control and exposure conditions for $\mathrm{tHg}$ levels in the brain. Statistically significant differences between means were considered when $p<0.05$. All graphs depict mean \pm standard error of the mean (SEM). For $\mathrm{Hg}(\mathrm{II})$ and $\mathrm{MeHg}$ experiments, the relationships between tHg levels in the brain (mean values) and the experimental time, considering exposure and post-exposure periods separately, were statistically tested using the Spearman correlation analysis. Linear regressions were considered significant for $p<0.05$.

\section{Results}

No fish mortality was observed during either of the exposure experiments. Though feeding behavior was not strictly monitored, no alterations were perceptible during and after treatment on fish feeding behavior. No significant differences were found between control and exposed fish for $\mathrm{K}$ values, with values ranging for $\mathrm{Hg}$ (II) and $\mathrm{MeHg}$ experiments, respectively, as 1.8-2.9 and 1.9-2.7.

\subsection{Mercury levels in fish brain}

Fig. 2 presents the variation of total $\mathrm{Hg}(\mathrm{tHg})$ in brain of white seabream exposed to $\mathrm{Hg}(\mathrm{II})$ or to $\mathrm{MeHg}$, as well as in control fish. $\mathrm{tHg}$ levels in brain of fish exposed to $\mathrm{Hg}$ (II) differed significantly $(p<0.05)$ between control and exposed fish after 3, 7 and 14 days of exposure, as well as in both post-exposure periods (PE14 and PE28). Concentrations of tHg increased significantly and progressively between E3, E7 and E14 ( $p=0.0013$ for E3 vs. E7 and $p<0.001$ for E7 vs. E14). tHg levels at PE14 and PE28 were identical to those found at E14 ( $p>0.05$ for E14 vs. PE14 and for E14 vs. PE28). Moreover, tHg levels in the post-exposure period never reached those found in control fish. No significant temporal variations were recorded for tHg in the control group.

Similarly, fish exposed via MeHg-contaminated feed displayed significantly increased tHg levels in brain just after 3 days (Fig. 2). Levels of tHg in brain sharply increased between 3 and 14 days of exposure when a maximum was reached. tHg levels at E14 and PE14 were similar $(p>0.05)$, while a significant decrease of $\mathrm{Hg}$ was recorded between E14 and PE28 $(p<0.05)$. As previously described for $\mathrm{Hg}$ (II) exposure, levels of tHg in previously exposed fish never reached values of control in the post-exposure period, and tHg in brain of control fish were relatively constant along the experiment.

The relationships between tHg levels in the brain and experimental time were represented in Fig. 3, with exposure and post-exposure periods being plotted separately. Total $\mathrm{Hg}$ levels increased linearly in the brain upon exposure to $\mathrm{Hg}(\mathrm{II})$ and $\mathrm{MeHg}$, while no significant associations between $\mathrm{tHg}$ and time were found in the post-exposure period for both $\mathrm{Hg}$ forms. Despite that common pattern, the accumulation rate of $\mathrm{Hg}$ in the brain, as represented by the $\mathrm{m}$ value, was one order of 
$\mathrm{Hg}(\mathrm{II})$ experiment

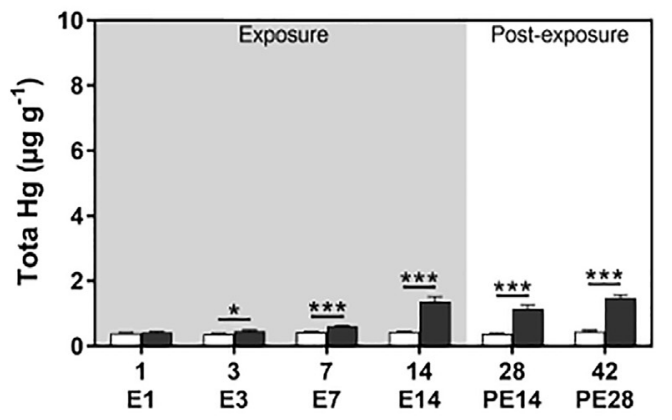

MeHg experiment

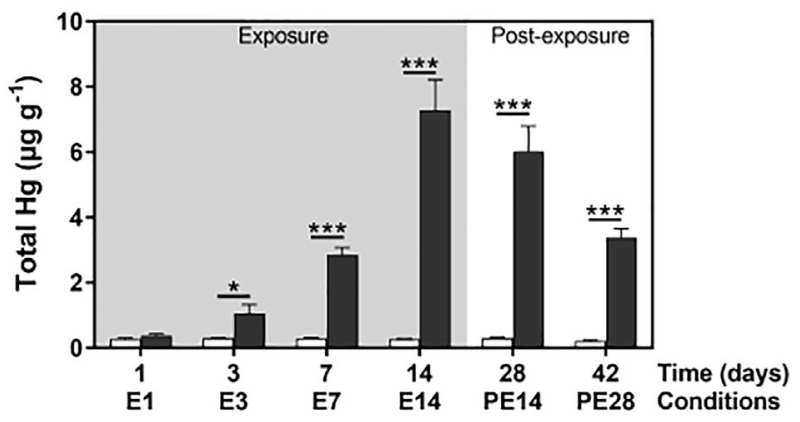

Control fish

Exposed fish

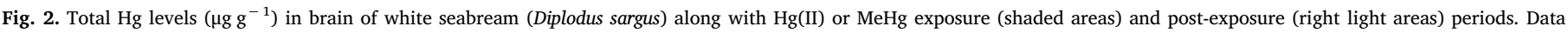

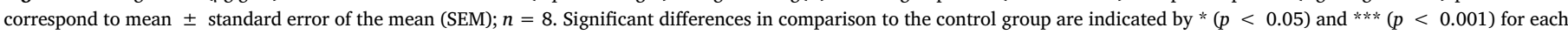

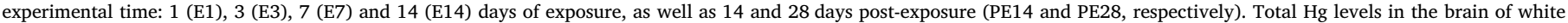
seabream exposed to $\mathrm{Hg}$ (II) were already published in Pereira et al. (2015).

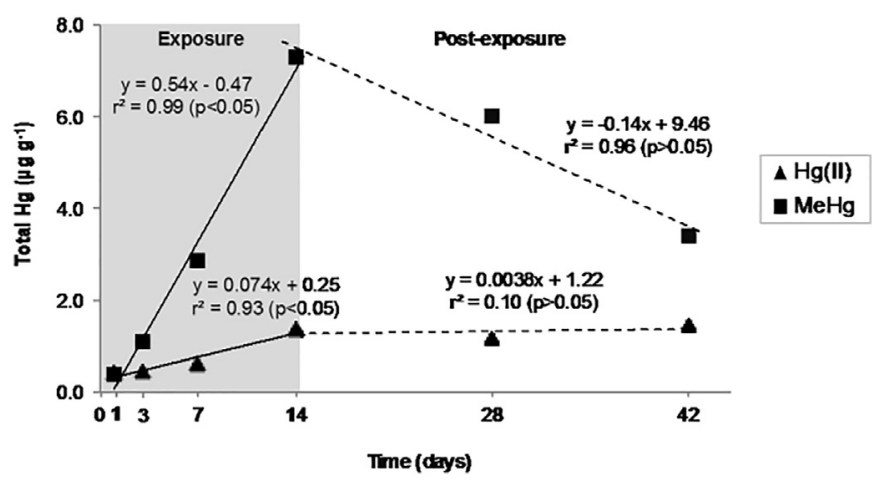

Fig. 3. Relationships between total $\mathrm{Hg}$ levels $\left(\mu \mathrm{g} \mathrm{g}^{-1}\right)$ in the brain of white seabream (Diplodus sargus) and the experimental time upon exposure to $\mathrm{Hg}$ (II) ( $\mathbf{\Delta}$ ) and to $\mathrm{MeHg}$ (ם). Exposure period (shaded area) and post-exposure period (light area) were plotted separately. Mean values were plotted for each experimental time; the linear regression equations were provided, as well as the $p$ value in relation with 0.05 cut off. Lines corresponding to non-significant correlations between tHg levels and time in the post-exposure period, both for $\mathrm{Hg}$ (II) and $\mathrm{MeHg}$ experiments, were represented in dashed.

magnitude higher following MeHg exposure (0.54 $\mu \mathrm{g} \mathrm{g}^{-1} /$ day) than $\mathrm{Hg}$ (II) $\left(0.074 \mu \mathrm{g} \mathrm{g}^{-1} /\right.$ day). In the post-exposure period, while tHg levels in the brain remain unchanged over time following $\mathrm{Hg}$ (II) exposure (as indicated by the $\mathrm{m}$ value closed to zero), it showed a tendency to decrease with time for $\mathrm{MeHg}$ exposure $\left(\mathrm{m}=-0.14 \mu \mathrm{g} \mathrm{g}^{-1} /\right.$ day) (although not significant).

\subsection{Antioxidants in fish brain}

The exposure of fish to $\mathrm{Hg}(\mathrm{II})$ led to an increase of brain SOD activity at E1 and E14, while CAT did not change significantly along the experimental time (Fig. 4). A decrease of brain GPx at E7 and PE14 was also recorded upon $\mathrm{Hg}(\mathrm{II})$ exposure, while at E14 an induction was found. Moreover, no significant changes of GST activities were found and GR only changed scarcely (with inductions at E1 and E7). Lastly, total glutathione content increased significantly in the last post-exposure time (PE28) upon exposure to $\mathrm{Hg}$ (II).

Exposure to MeHg was able to increase significantly brain SOD activities at almost all experimental times (except E1 and E7) together with CAT activities at E1, E3, E14 and PE28. Accordingly, GPx activity expressed enhancements at E3 and E14, while GST exhibited inductions over the experimental time (E1, E14, PE14 and PE28). MeHg was also on the basis of a GR induction at E3 and inhibitions at E7 and PE14, while tGSH decreased at E1 and increased at E14.

\subsection{Oxidative damage indicators in fish brain}

No lipid peroxidation occurred after exposure of fish to $\mathrm{Hg}(\mathrm{II})$, while a significant increase of protein oxidation was recorded at E1, E3, E7 and PE14 (Fig. 5). In general, MeHg did not elicit significant alterations on damage endpoints, except at E3 when an increase of LPO was found, and at PE14 when a significant increase of protein oxidation occurred. Moreover, levels of protein oxidation decreased significantly in the brain of exposed fish at PE28.

\section{Discussion}

\subsection{Comparative analysis of $\mathrm{Hg}(\mathrm{II})$ and $\mathrm{MeHg}$ bioaccumulation in fish} brain

High accumulation of $\mathrm{Hg}$ was previously found in the brain of fish from polluted areas (Mieiro et al., 2011; Pereira et al., 2014); however, these field studies did not examine the rates of $\mathrm{Hg}$ accumulation in fish brain, its temporal profile, or the impacts of different $\mathrm{Hg}$ species. These are some of the scientific gaps that this study attempts to fill, appearing as the first dedicated to a comparative and temporal evaluation of the neurotoxicity of $\mathrm{Hg}$ (II) and $\mathrm{MeHg}$ in fish under realistic levels and exposure routes. Moreover, the comparable daily exposure levels achieved for waterborne $\mathrm{Hg}$ (II) [265 $\mu \mathrm{g} \mathrm{Hg}$ (II)/day/ $\mathrm{kg}$ of body weight] and dietary $\mathrm{MeHg}$ [261 $\mu \mathrm{g} \mathrm{MeHg/day/kg} \mathrm{of} \mathrm{body} \mathrm{weight]} \mathrm{allows} \mathrm{par-}$ allel interpretations on the accumulation dynamics and toxicity of both $\mathrm{Hg}$ forms.

Interestingly, $\mathrm{tHg}$ levels increased significantly in the $D$. sargus brain upon exposure to $\mathrm{Hg}(\mathrm{II})$ and $\mathrm{MeHg}$ right after 3 days of exposure, suggesting a similar initial uptake dynamic of both $\mathrm{Hg}$ forms. Despite that, the accumulated levels of tHg in the brain were consistently higher upon exposure to $\mathrm{MeHg}$ than to $\mathrm{Hg}$ (II) (from E3 until the end of the post-exposure period). This indicates a higher uptake rate by the brain for $\mathrm{MeHg}$ in comparison with $\mathrm{Hg}(\mathrm{II})$. In fact, linear regressions between $\mathrm{tHg}$ in the brain and time of exposure (i.e., between E1 and E14) were searched, as previously described in Wang et al. (2010), with the slope depicting the estimated accumulation rate. Thus, $\mathrm{MeHg}$ accumulation rate in the brain was almost one order of magnitude higher than that estimated for $\mathrm{Hg}(\mathrm{II})$. These results are in line with the previous findings of Wang et al. (2010) for the whole fish body, denoting the higher propensity of brain to accumulate $\mathrm{MeHg}$ over time compared to $\mathrm{Hg}(\mathrm{II})$. Indeed, tHg levels after 14 days of exposure to MeHg were 5 times higher than those recorded for $\mathrm{Hg}$ (II) exposure. Current data are in agreement with accumulated levels of $\mathrm{Hg}$ (II) and $\mathrm{MeHg}$ measured in zebrafish brain upon a dietary exposure to both $\mathrm{Hg}$ forms with levels of MeHg being almost 50 times higher than $\mathrm{Hg}$ (II) (Gentès et al., 2015). In 

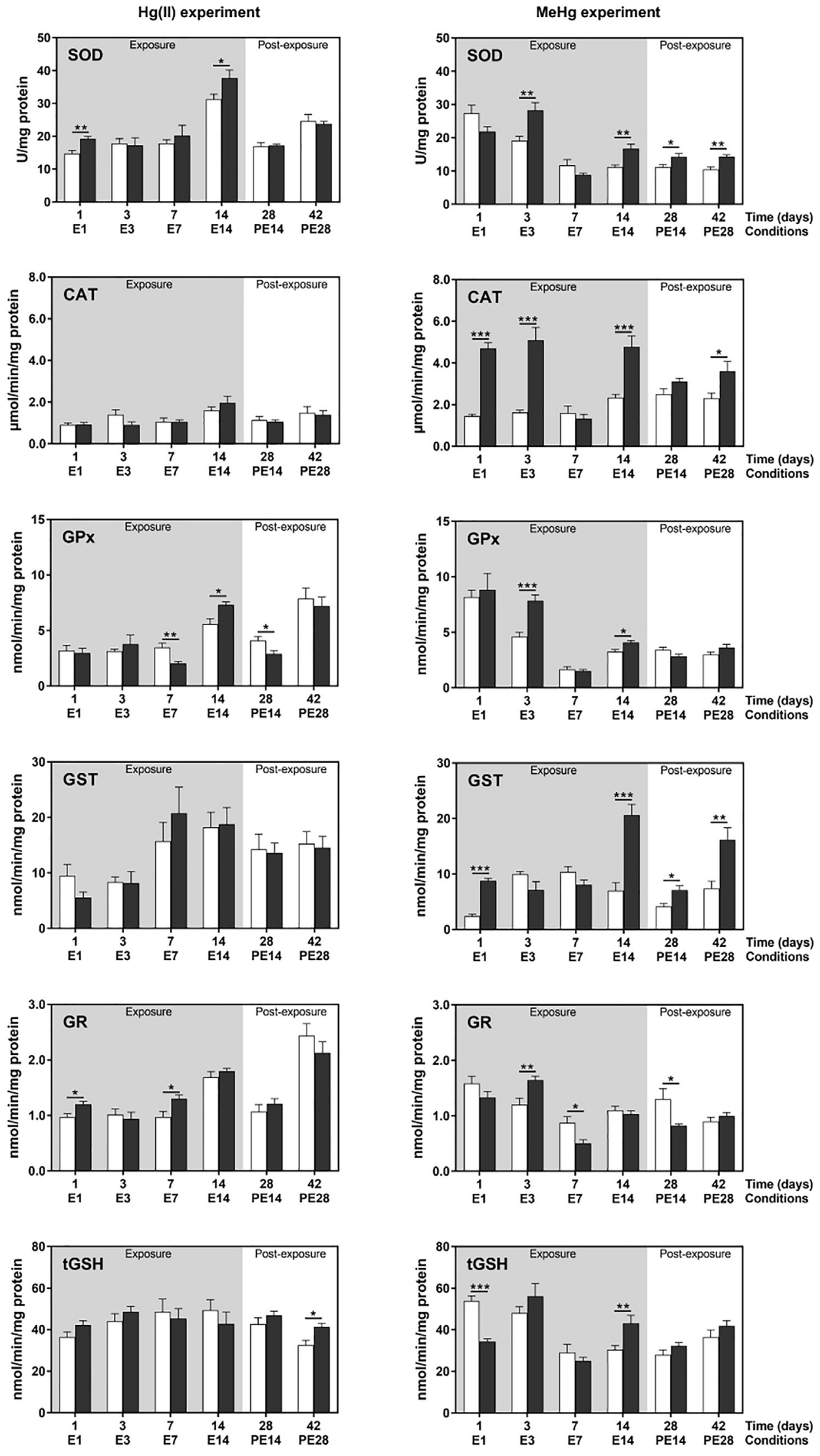

Fig. 4. Activities of superoxide dismutase (SOD), catalase (CAT), glutathione peroxidase (GPx), glutathione S-transferase (GST) and glutathione reductase (GR), plus levels of total glutathione (tGSH) in the brain of white seabream (Diplodus sargus) along with $\mathrm{Hg}$ (II) or MeHg exposure (shaded areas) and post-exposure (right light areas) periods. Data correspond to mean \pm standard error of the mean (SEM); $n=8$. Significant differences in comparison to the control group are indicated by $*(p<0.05), * *(p<0.01)$ and $* * *(p<0.001)$ for each experimental time, namely: 1 (E1), 3 (E3), 7 (E7) and 14 (E14) days of exposure, as well as 14 and 28 days post-exposure (PE14 and PE28, respectively). 
$\mathrm{Hg}$ (II) experiment
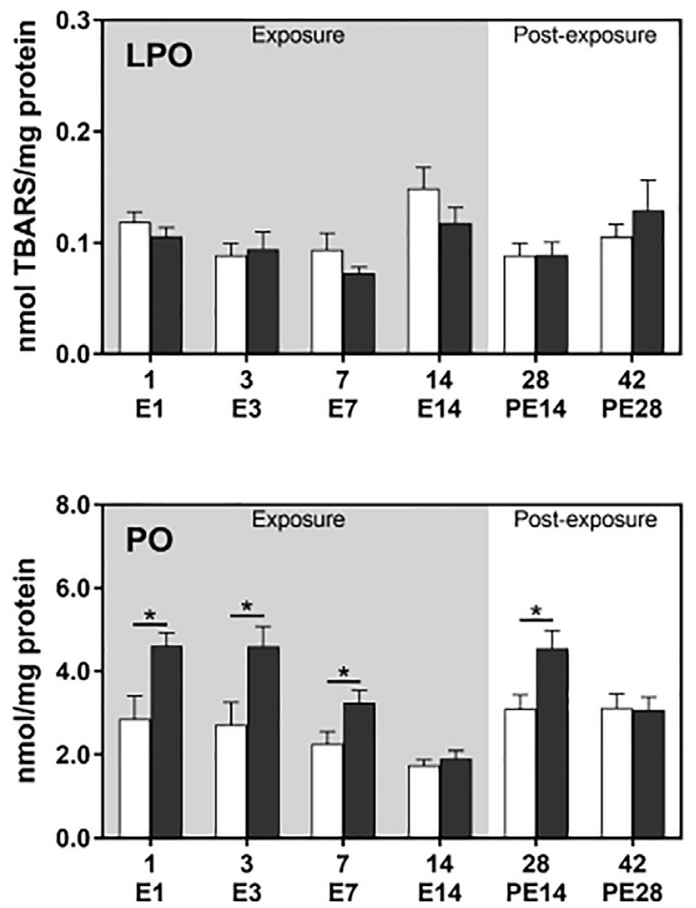

MeHg experiment
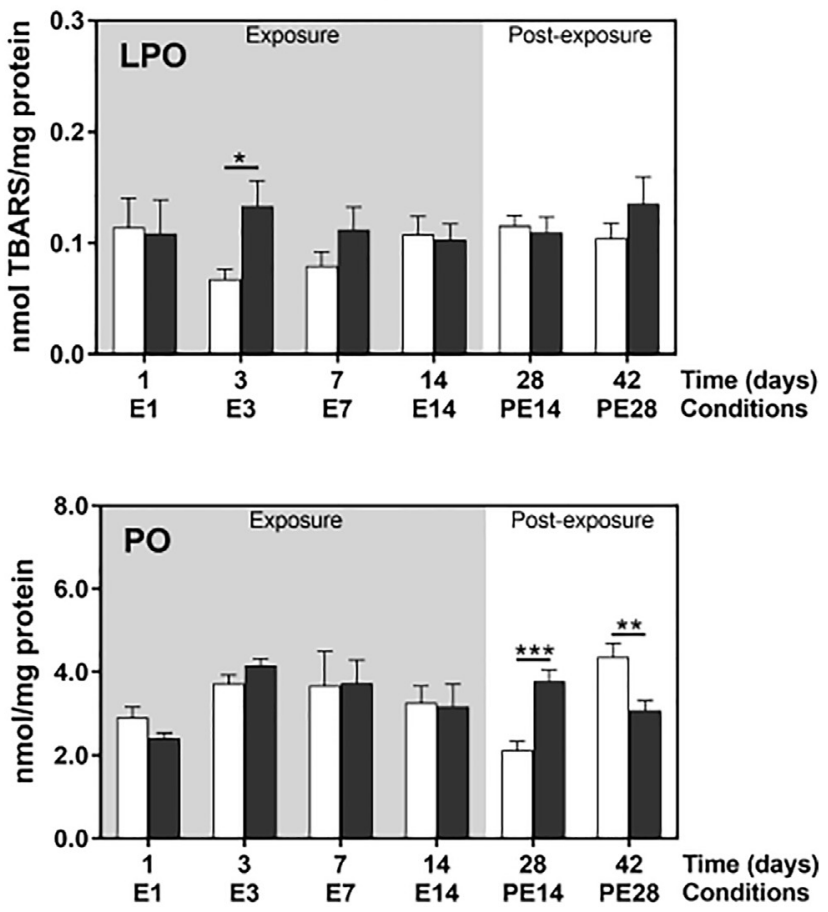

Exposed fish

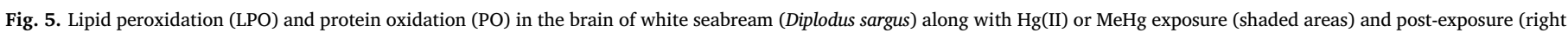

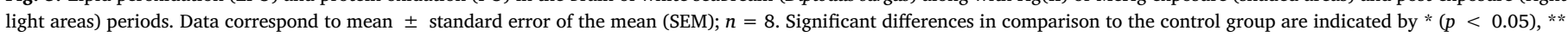

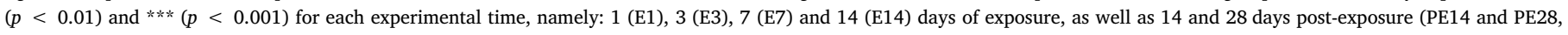
respectively).

the same direction, Korbas et al. (2012) found a higher accumulation of $\mathrm{Hg}$ in zebrafish brain upon exposure to $\mathrm{MeHg}$ than $\mathrm{Hg}(\mathrm{II})$ species. Likewise, levels of $\mathrm{Hg}$ were one order of magnitude higher in the brain of Atlantic salmon for $\mathrm{MeHg}$ comparing to $\mathrm{Hg}(\mathrm{II})$, both dietary exposed (Berntssen et al., 2003).

The speciation of mercury governs its assimilation, distribution and toxicity in organisms. With this in mind, the tHg levels that were found in the brain of $D$. sargus upon exposure to $\mathrm{Hg}(\mathrm{II})$ and $\mathrm{MeHg}$ through the water and diet, respectively, were likely controlled by three interlinked mechanisms, namely: (i) the uptake rate from the external matrix, (ii) the relative distribution between the different fish tissues/organs, and (iii) the bioaccessibility of the mercury species to the brain, which is largely controlled by the ability to cross the blood brain barrier (BBB).

It is recognized that estimation of daily uptake should consider the concentration in the matrix (water or feed, in the current study), the matrix intake rate and the route-specific uptake efficiency (the fraction of $\mathrm{Hg}$ that reaches the systemic circulation) (Li et al., 2015). This calculation is not within the goals of the present study, but elevated uptake rates were already described for $\mathrm{MeHg}$ in the intestine (Andres et al., 2002; Leaner and Mason, 2002). It has been reported that the flux of $\mathrm{MeHg}$ (as $\mathrm{CH}_{3} \mathrm{HgCl}$ ) across the intestinal epithelia occurs both as passive (diffusion) and energy dependent uptake (Andres et al., 2002; Leaner and Mason, 2002). MeHg can form a complex with cysteine being then taken up in the intestinal epithelia via the energy dependent L-neutral amino acid carrier (Leaner and Mason, 2002). In terms of $\mathrm{Hg}$ (II), the drastic daily decrease in $\mathrm{Hg}$ levels in the exposure water (up to $2.5-18 \%$ of the initial concentration; measured before recontamination) also suggests a substantial uptake of this $\mathrm{Hg}$ form, most likely via gills. Interestingly, $\mathrm{Hg}$ (II) and $\mathrm{MeHg}$ also converge in the transport processes described for uptake in the intestinal and gills epithelium, respectively. It looks like $\mathrm{Hg}$ (II) can be taken up in fish gills through passive diffusion (as uncharged chloride complexes, likely to occur in seawater) and physiologically regulated transport (Glynn et al., 1994;
Klinck et al., 2005). Klinck et al. (2005) described the ability of Hg(II) to bind strongly to fish gills due to the presence of sulfur groups and the high $\log \mathrm{K}_{\mathrm{Hg}-\text { gill. }}$. In addition, our recent publication (Pereira et al., 2015) also reported a rapid increase of tHg levels in gills of $D$. sargus exposed to $\mathrm{Hg}$ (II), occurring just after 1 day of exposure.

The literature refers to a more efficient uptake rate of $\mathrm{MeHg}$ in comparison to $\mathrm{Hg}$ (II) (Wang and Wong, 2003; Pickhardt et al., 2006), attributed to the high lipophilic character of the organic form, and thus, to a high permeability across the cell membrane. In contrast, the bioaccumulation of $\mathrm{Hg}(\mathrm{II})$ is classically regarded as of minor importance due to its low lipophilicity. However, as noted by Mason et al. (1996), the differences in lipid solubility alone cannot account for the predominance of $\mathrm{MeHg}$ in fish tissues. On the other hand, Andres et al. (2002) stated that the flux across the gills and intestine could be similar for $\mathrm{Hg}(\mathrm{II})$ and $\mathrm{MeHg}$. Korbas et al. (2012) provided an identical conclusion through the calculation of the membrane permeability in zebrafish for $\mathrm{Hg}(\mathrm{II})$ and $\mathrm{MeHg}$. Indeed, in absence of L-cysteine in the treatment solutions, the net rate of $\mathrm{Hg}(\mathrm{II})$ movement across the zebrafish larval body (e.g. through the gills, the skin, or the gastrointestinal tract) would be similar or even slightly higher than for organic mercury forms (Korbas et al., 2012). Keeping this in mind, the uptake of $\mathrm{Hg}$ (II) and $\mathrm{MeHg}$ from the external matrices does not seem to be the primary variable resulting in differences in $\mathrm{Hg}$ accumulation in $D$. sargus brain. As such, another aspect of mercury speciation toxicokinetics must explain the higher propensity of the brain to accumulate $\mathrm{MeHg}$ in comparison to $\mathrm{Hg}$ (II).

Upon crossing the first $D$. sargus membrane barrier from the external medium, the probable form of $\mathrm{Hg}(\mathrm{II})$ and $\mathrm{MeHg}$ would be a thiolatebased one that can be distributed by the different tissues/organs, as described for zebrafish larvae (Korbas et al., 2012). The complexes of $\mathrm{Hg}(\mathrm{II})$ and $\mathrm{MeHg}$ with thiol groups should move differently across the cells, explaining the higher levels of tHg found in the white seabream brain after $\mathrm{MeHg}$ exposure in comparison with $\mathrm{Hg}(\mathrm{II})$. This hypothesis 
is supported by findings in lens epithelial cells of zebrafish where the increased permeability of the thiol bound $\mathrm{MeHg}$ vs. its $\mathrm{Hg}$ (II) counterpart cannot explain per se the higher levels of $\mathrm{Hg}$ upon exposure to the former (Korbas et al., 2012). In fact, $\mathrm{MeHg}$ forms a complex with cysteine that mimics the large neutral amino acid methionine, promoting the easy transport of $\mathrm{MeHg}$ into the cells by the neutral amino acid carriers (Clarkson and Magos, 2006). MeHg-cysteine complexes can be distributed to all tissues, including the brain by crossing readily the endothelial cells of the BBB (Clarkson et al., 2007). An identical transport mechanism could be hypothesized for fish even if it was never demonstrated before. This MeHg-cysteine complex is water-soluble, and thus the mobility of $\mathrm{MeHg}$ in the organisms is not related with its lipophilicity, as greatly reviewed by Clarkson and Magos (2006) and already pointed out in this discussion.

In contrast to $\mathrm{MeHg}$, the mechanisms of $\mathrm{Hg}$ (II) transport in organisms remain elusive (Clarkson and Magos, 2006). No comprehensive studies exist on the transport of $\mathrm{Hg}(\mathrm{II})$ from the gills in fish to target organs, namely the brain, preventing a full interpretation of $D$. sargus data. Given the circulatory system of fish, gills would be a more direct uptake-route of $\mathrm{Hg}$ to the brain, while intestinal absorption, followed by a preferential transport into the liver (via hepatic portal system), would potentially result in a retarded or diminished $\mathrm{Hg}$ accumulation in the brain. However, current data does not support this assumption since higher levels of tHg were found in the brain upon dietary exposure to $\mathrm{MeHg}$ in comparison with waterborne exposure to $\mathrm{Hg}(\mathrm{II})$, pointing out the previous arguments on the high mobility of $\mathrm{MeHg}$ in the organisms regardless the absorptive tissue. Among the poor knowledge on $\mathrm{Hg}$ (II) transport, glutathione was identified as one of the transporters of $\mathrm{Hg}$ (II) in the organisms. It is known that $\mathrm{Hg}$ (II) is released into the bile as a complex with reduced glutathione. Presumably the thiol ligands of two glutathione molecules attach to $\mathrm{Hg}(\mathrm{II})$ to form a structure that resembles that of oxidized glutathione and that is exported from the liver cells on glutathione carriers.

Hypothesizing a comparable uptake rate for both $\mathrm{Hg}$ forms, the higher accumulation of $\mathrm{MeHg}$ observed in D. sargus brain comparing to $\mathrm{Hg}$ (II) suggests the existence of other tissues/organs where this $\mathrm{Hg}$ form can be preferentially accumulated. In this direction, kidney has been demonstrated as the main depository of $\mathrm{Hg}$ (II) compounds, accounting for $50-90 \%$ of the body burden of animals (WHO, 1991).

A very interesting finding was provided by the post-exposure period, since tHg did not change significantly along the 28 days of recovery after $\mathrm{Hg}$ (II) exposure. In contrast, after exposure to $\mathrm{MeHg}, \mathrm{tHg}$ levels decreased considerably at PE28 in comparison with PE14 and E14. These results revealed that $\mathrm{Hg}$ (II) is very stable over time in the brain, which is probably related to the formation of a complex with selenium (mercuric selenide - HgSe) that is very difficult to be eliminate (Korbas et al., 2010). Complexation of $\mathrm{Hg}$ (II) as $\mathrm{HgSe}$ was hypothesized as a detoxification mechanism of $\mathrm{Hg}$ based on the eventual non-toxicity of the complex to the cells (MacDonald et al., 2015). A slow elimination of $\mathrm{Hg}$ species (including $\mathrm{Hg}(\mathrm{II})$ ) was previously reported in zebrafish (Korbas et al., 2012) in agreement with results of this study on $D$. sargus. Current data confirmed also that brain is a final target-organ for $\mathrm{Hg}$ (II), as previously suggested for tilapia that accumulated significant levels of $\mathrm{Hg}$ (II) in the head at the end of 30 days of depuration (Wang et al., 2010). Hg(II) can cross the BBB bi-directionally, but its influx and efflux from brain is probably unbalanced, leading to accumulation over time, as previously described for iron (Chen et al., 2014).

The considerable decrease of $\mathrm{tHg}$ in brain of $D$. sargus at PE28 in the $\mathrm{MeHg}$ exposure is most probably due to its elimination. This hypothesis is supported by results from a parallel study that reported a very low percentage $(<1.5 \%)$ of $\mathrm{Hg}$ in the brain of fish exposed to $\mathrm{MeHg}$ was in the form of $\mathrm{Hg}(\mathrm{II})$, suggesting low amounts of demethylation (Puga et al., 2016). After 28 days of depuration, levels in the brain decreased to half of those recorded at E14. This is in line with the estimation of a $\mathrm{MeHg}$ half-life in the brain of captive mink of 15.4 days (Evans et al.,
2016). In fact, in vitro studies performed by Kerper et al. (1996) with bovine brain capillary endothelial cells, which constitute the BBB, revealed that the complexation of $\mathrm{MeHg}$ with GSH and subsequent transport of the complex by an ATP-independent mechanism might be involved in the transport of $\mathrm{MeHg}$ out of brain endothelial cells. There are a few reports of $\mathrm{MeHg}$ elimination in fish brain. However, after 28 days of $\mathrm{MeHg}$ elimination by sweetlips, a significant fraction of this form was still found in fish head probably associated with the brain nervous system (Wang and Wong, 2003).

\subsection{Alterations of the redox-defense system in fish brain upon accumulation of $\mathrm{Hg}$ (II) and $\mathrm{MeHg}$}

The mechanism(s) of $\mathrm{Hg}$ (II) toxicity in fish brain is not completely understood yet, but a few studies with rodents reported changes in oxidative stress related-endpoints (Hussain et al., 1997; El-Demerdash, 2001). In contrast, the neurotoxicity of $\mathrm{MeHg}$ has been widely attributed to the induction of oxidative stress by either the overproduction of ROS or by the reduction of the oxidative defense capacity (Ceccatelli et al., 2010). The binding of MeHg to GSH due to its high affinity for SH-groups decreases the ability of this non-enzymatic antioxidant to protect the cells from the free-radical mediated damage. Thus, the enhancement of oxidative stress upon $\mathrm{MeHg}$ accumulation in the brain is quite well described for rodents (Mori et al., 2007; Stringari et al., 2008; Franco et al., 2009; Zemolin et al., 2012), even if it is less reported in fish (Berntssen et al., 2003; Mieiro et al., 2011). Interestingly, the significant accumulation of $\mathrm{Hg}$ (II) in $D$. sargus brain did not lead to substantial alterations of antioxidants, whereas CAT and GST were totally unresponsive to $\mathrm{Hg}$ (II) presence over time (see Table 1). In contrast, $\mathrm{MeHg}$ exposure resulted in significant enhancement of antioxidant activities (including CAT and GST) in exposure and post-exposure periods.

It was observed that, SOD and CAT activities increased concurrently with MeHg exposure (particularly at E3 and E14) and 28 days of postexposure (Table 1), indicating an adjustment to the pro-oxidant challenge. In addition, $\mathrm{MeHg}$ exposure led to an enhancement of SOD at PE14 that coincides with the highest levels of $\mathrm{Hg}$ in the brain. Interestingly, CAT was also enhanced at E1, suggesting that an adaptive response to $\mathrm{MeHg}$ even before a significant accumulation could be noticed, which points out the elevated sensitivity of antioxidants and thus the ability to signalize insults. Berntssen et al. (2003) also found a significant increase of SOD activity in the brain of salmon fed with $5 \mathrm{\mu g} \mathrm{g}^{-1}$ of $\mathrm{MeHg}$ (similar exposure levels to D. sargus), speculating that it was an adaptive response to $\mathrm{MeHg}$, which would prevented lipid peroxidation. In contrast, in $D$. sargus exposed to $\mathrm{Hg}$ (II) it was found that SOD brain only increased sporadically (E1 and E14), pointing out the poor responsiveness as previously uncovered in salmon by the absence of SOD changes following a dietary exposure to $\mathrm{Hg}$ (II) (Berntssen et al., 2003). Accordingly, CAT was totally unresponsive to $\mathrm{Hg}(\mathrm{II})$ accumulation in $D$. sargus brain, as previously stated. The poor activation of the brain antioxidant defense system upon $\mathrm{Hg}$ (II) exposure was also unveiled by GST, which did not change in exposed fish over time (Table 1). In contrast, brain GST activity of D. sargus increased after exposure to MeHg (namely, E1 and E14), as well as in both post-exposure periods (PE14 and PE28), confirming an adaptive response to the pro-oxidant conditions.

While most of the antioxidants displayed low responsiveness to $\mathrm{Hg}$ (II) in D. sargus brain, a different scenario was observed for GPx that displayed activity decreases at E7 and PE14 (Table 1), evidencing a breakdown of the antioxidant defense system and thus a potential adverse effect of $\mathrm{Hg}(\mathrm{II})$. GPx catalyzes the hydrogen peroxide into water with the concomitant conversion of reduced glutathione (GSH) to its oxidized form - glutathione disulfide (GSSG). Moreover, it is an active scavenger of free radicals, and hence it is strongly involved in protecting against potential cell injury and neuropathological conditions (Hussain et al., 1999). Activity of GPx also declined in a dose-dependent manner in the cerebellum of rat exposed to $\mathrm{HgCl}_{2}$ (Hussain et al., 1999). 
Table 1

Synopsis of the brain oxidative stress profiles upon fish exposure to $\mathrm{Hg}$ (II) and $\mathrm{MeHg}$ Significant alterations are marked by up and down arrows meaning increased or decreased levels of the parameter, respectively. Information of the meaning of each alteration is depicted in the arrow's color.

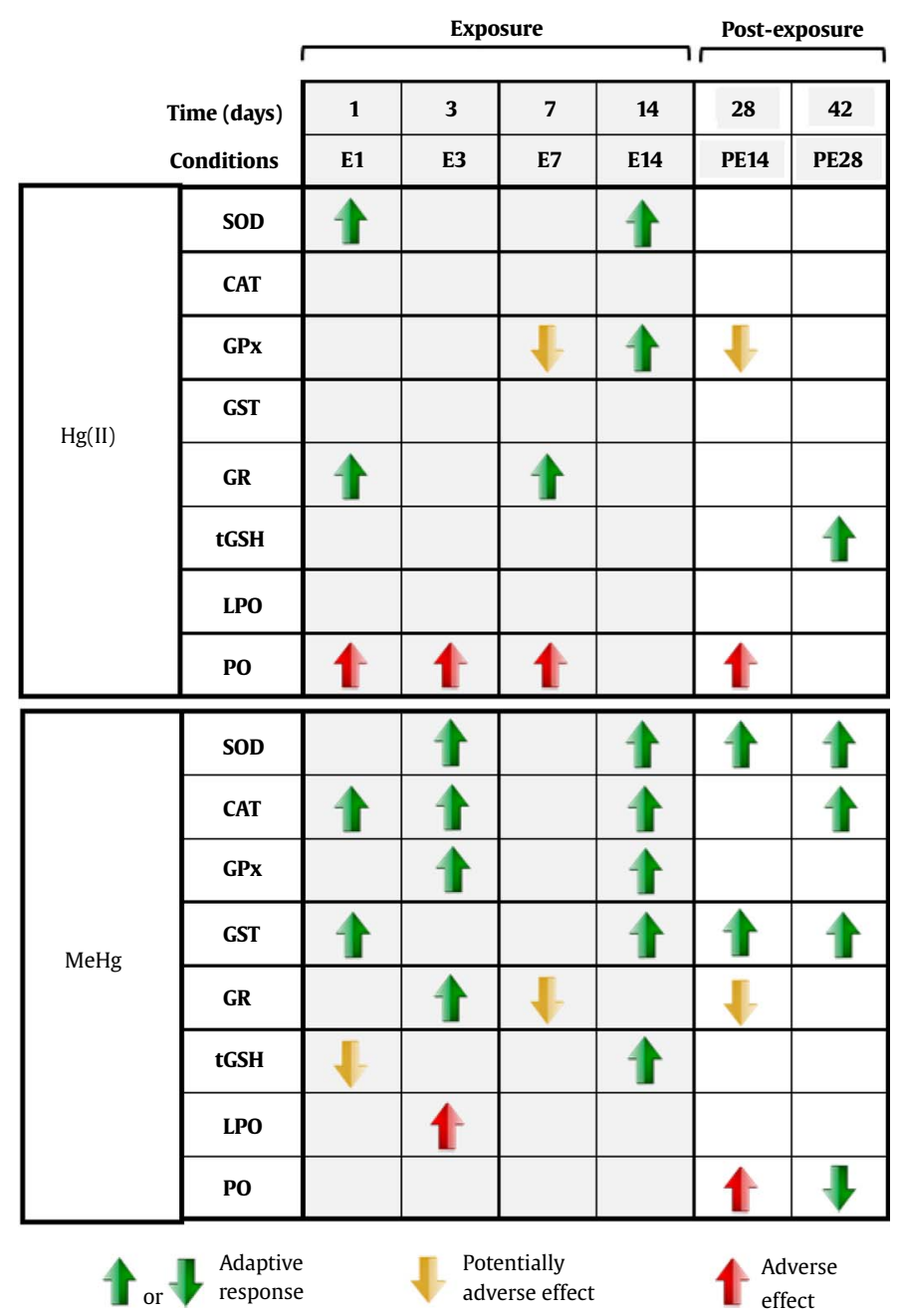

As previously stated, $\mathrm{Hg}$ (II) is probably accumulated in the brain as a mercuric selenide that behaves like an inert complex in the cells (Korbas et al., 2010). Nevertheless, the formation of this complex can interfere with enzymes that are dependent on selenium (Se) such as GPx. In this context, a combined exposure of $\mathrm{Hg}$ (II) (as $\mathrm{HgCl}_{2}$ ) and Se in rats promoted an alleviation of toxic effects of $\mathrm{Hg}(\mathrm{II})$ on different antioxidant enzymes, pointing out that Se could antagonize the toxic effects of $\mathrm{Hg}(\mathrm{II})$ (El-Demerdash, 2001). In parallel with this study, the time-course variation of Se accumulation in $D$. sargus brain was investigated at the light of its key role in $\mathrm{Hg}$ (II) sequestration and mitigation of its toxicity (Raimundo et al., unpublished). Brain Se levels remained relatively unaltered over time, meaning that GPx decreases at E7 and PE14 were not related with a lack of Se. Alternatively, GPx was most probably inhibited at those time-points by the $\mathrm{Hg}$ (II) binding to GPx sulphydryl groups, which could change its shape and blocking its activity, as generally described for transition metals like $\mathrm{Hg}$ (Ercal et al., 2001).

Changes of GPx on D. sargus brain exposed to $\mathrm{Hg}$ (II) were timedependent since a significant induction was found at the end of the exposure period (E14), while inhibitions occurred at E7 and PE14. Apparently, variations of GPx are not strictly related with the $\mathrm{Hg}$ accumulation since at E14 and PE14 similar levels were recorded in brain of exposed fish. In contrast, at E3 and E14, MeHg led to an induction of brain GPx in $D$. sargus and no vulnerability towards inhibition was perceptible. As pointed out by SOD, CAT and GST, also GPx disclosed an adaptive response to $\mathrm{MeHg}$ accumulation in $D$. sargus brain.

The induction of brain GR at E1 and E7 in fish exposed to $\mathrm{Hg}$ (II) revealed a challenge to the GSH/GSSG balance (Table 1). Higher GR activities at E7 coincided with an elevated accumulation of $\mathrm{Hg}$ in the brain pointing out an adaptive response to $\mathrm{Hg}$ (II). In light of the great sensitivity of antioxidants response to toxicants, as previously claimed for CAT it is probable that GR enhancement at E1 reflects an early effect, perceptible even before the detection of significant $\mathrm{Hg}$ accumulation. GR activity also increased considerably in the white seabream brain after 3 days of exposure to $\mathrm{MeHg}$, suggesting an adaptive response to this $\mathrm{Hg}$ form, which is in accordance with other antioxidant's change. Moreover, this result is in line with several studies that reported elevated GR activities in aquatic organisms exposed to pro-oxidant stressors (e.g. Regoli et al., 2002). Particularly, in fish (Liza aurata) brain it was found an induction of GR in a field exposure to $\mathrm{Hg}$ (including MeHg) (Mieiro et al., 2011). Besides that, the higher accumulation of MeHg at E7 and PE14 was on the basis of GR activity decreases, which is a potential indication of $\mathrm{MeHg}$ toxicity as previously observed in mice (Stringari et al., 2008). The inhibition of GR can imply an accumulation of GSSG that would be eliminated from the cell due to its toxicity, resulting then in a tGSH decrease. Currently, despite 
decreases of GR activity upon MeHg exposure there was no compromise of tGSH levels at these time-points as further discussed.

Distinct variation patterns were also found for tGSH upon fish exposure to $\mathrm{Hg}(\mathrm{II})$ and $\mathrm{MeHg}$ (Table 1). While tGSH did not respond to $\mathrm{Hg}$ (II) accumulation in brain over time (except at PE28) as observed for the majority of antioxidants, occasional variations were found during exposure to $\mathrm{MeHg}$. The protective effects of GSH are related to its activity as a buffer system that limits the amount of $\mathrm{MeHg}$ available for the interaction with sensitive macromolecules, and its ability as a ROS scavenger. Thus, the supply of GSH precursors to neurons via astrocytes and the maintenance of intracellular GSH concentrations are critical to protect cells against MeHg-induced neurotoxicity (Farina et al., 2012). The decrease of tGSH at E1 occurred even before significant $\mathrm{Hg}$ accumulation was measured in the brain, meaning an early response to $\mathrm{MeHg}$ exposure and reflecting the great sensitivity of GSH antioxidant system. Keeping in view the direct chemical interaction between $\mathrm{MeHg}$ and GSH, forming GS- $\mathrm{HgCH}_{3}$ complexes (Dutczak and Ballatori, 1994), it is likely that the observed decrease in brain tGSH levels in MeHgexposed fish is related, at least in part, to the formation of GS- $\mathrm{HgCH}_{3}$ as described for mice (Stringari et al., 2008). On the contrary, MeHg accumulation peaked at E14 coinciding with the enhancement of tGSH, pinpointing an activation of antioxidant defenses to counteract the MeHg-induced pro-oxidant pressure. Current data on tGSH did not indicate the $\mathrm{MeHg}$ elimination over time in the form of $\mathrm{GS}-\mathrm{HgCH}_{3}$ conjugates, since it would probably imply a significant decrease of tGSH levels (that was only recorded at E1). Hence, considering that, in the $\mathrm{MeHg}$ experiment, $\mathrm{Hg}$ levels decreased significantly in the brain during the post-exposure period, an alternative elimination pathway should be considered.

Overall, $\mathrm{MeHg}$ consistently activated the brain antioxidant defenses, pinpointing an adaptive response to this $\mathrm{Hg}$ form in fish. Oppositely, the antioxidant defenses were barely responsive to $\mathrm{Hg}(\mathrm{II})$ exposure (Table1). Considering that $\mathrm{Hg}$ is the toxic component common to both forms, it should be hypothesized that the distinct protection pattern found for $\mathrm{Hg}$ (II) and $\mathrm{MeHg}$ could be related with the metal accumulation threshold, able to induce a response of the antioxidant defense system. Exploring this hypothesis, it should be noticed that $\mathrm{Hg}$ levels in the brain after 14 days of exposure to $\mathrm{Hg}$ (II) (mean value of $1.4 \mu \mathrm{g} \mathrm{g}^{-1}$ ), as well as at PE14 and PE28 (mean values of $1.1 \mu \mathrm{g} \mathrm{g}^{-1}$ and $1.5 \mu \mathrm{g} \mathrm{g}^{-1}$, respectively) were comparable to those recorded for $\mathrm{MeHg}$ exposure at E3 $\left(1.1 \mu \mathrm{g} \mathrm{g}^{-1}\right)$. Despite that, distinct responses of the antioxidant defense system were found for those time-points [activation for $\mathrm{MeHg}$ vs. unresponsiveness to $\mathrm{Hg}(\mathrm{II})]$, pinpointing that the $\mathrm{Hg}$ threshold could not explain per se the different patterns found for both $\mathrm{Hg}$ forms. Therefore, it gains plausibility an alternative hypothesis relying on the specificity of toxicity mechanisms associated to organic and inorganic $\mathrm{Hg}$ forms.

\subsection{Oxidative damage and its association with antioxidant defenses}

Brain is highly vulnerable to LPO because it is a fatty rich organ. Thus, this type of damage has been proposed as an additional mechanism of $\mathrm{Hg}$ induced neurotoxicity in rats (Yee and Choi, 1996). Indeed, several studies with rodents reported an increase of LPO in brain after exposure to $\mathrm{Hg}$ (II) (El-Demerdash, 2001) as well as to $\mathrm{MeHg}$ (Glaser et al., 2010). Moreover, some studies described increase of LPO in fish brain upon exposure to MeHg (Berntssen et al., 2003). In general, no LPO occurred in D. sargus brain after accumulation of $\mathrm{Hg}$ (II) and $\mathrm{MeHg}$.

The compromise of the glutathione antioxidant system in $D$. sargus brain upon $\mathrm{Hg}(\mathrm{II})$ accumulation, as perceived by a GPx decrease at E7 and P14, did not led to LPO probably because of the protection afforded by other antioxidants (e.g. cysteine, alpha tocopherol and ascorbic acid; not measured in this study). As previously claimed, GPx could be selectively inhibited by $\mathrm{Hg}(\mathrm{II})$ associated with its Se-dependence, while other antioxidants kept their functionality, providing protection to the lipids of brain cells. Differently, it is very plausible that the strong activation of antioxidant defenses, namely SOD, CAT, GPx and GST activities, after the exposure to MeHg, prevented LPO (except at E3).

In the $\mathrm{Hg}(\mathrm{II})$ experiment, a significant enhancement of carbonyl groups occurred at E1, E3, E7 and PE14 together with a general unresponsiveness of antioxidants (Table 1). Carbonyl groups can be introduced in proteins by different pathways, mostly by metal catalyzed oxidation (Almroth et al., 2005), but also by secondary mechanisms associated with reactions of free radicals with other cellular constituents, namely lipids (Grune, 2000), where the highly oxidizable lipids can attack nearby proteins resulting in the formation of an excess of protein carbonyl groups (Almroth et al., 2005). In this study, an increase of carbonyl groups was not accompanied by lipid peroxidation in the $\mathrm{Hg}$ (II) experiment, giving support to the first hypothesis. An increase of carbonyl groups was previously well-correlated with protein damage caused by oxidative stress (Shacter et al., 1994). The formation of carbonyl derivatives is non-reversible, causing conformational changes, decreased catalytic activity in enzymes and, ultimately, resulting in the breakdown of proteins by proteases due to increased susceptibility (Almroth et al., 2005). Taking into account the deleterious effects of peroxide and peroxide-derived radicals in the CNS (Dringen et al., 2005), it is not surprising that the disruption of the GSH antioxidant system (as proposed by GPx inhibition) due to $\mathrm{Hg}$ (II) could result from the protein damage of $D$. sargus brain. Noteworthy, there was a temporal coincidence of brain GPx inhibition and protein damage (i.e. at E7 and PE14) upon exposure to $\mathrm{Hg}(\mathrm{II})$. A number of neurodegenerative diseases (e.g. Alzheimer and Parkinson) have been largely associated with an accumulation of protein oxidation products in brain cells over time (Smith et al., 1992). In this light, the oxidation of proteins found in $D$. sargus brain denotes a severe compromise of its functioning due to $\mathrm{Hg}(\mathrm{II})$ exposure. In contrast, results of carbonyl groups after MeHg exposure are in line with those of LPO. This substantiates the idea that an enhancement of antioxidant defenses prevented oxidative damage.

In an attempt to hierarchize the neurotoxic potential of $\mathrm{Hg}$ (II) and $\mathrm{MeHg}$ based on their pro-oxidant action, the degree of exposure and the incidence or severity of effects should be accounted for. In this line of thought, if the degree of exposure is assumed to be the $\mathrm{Hg}$ external exposure, it can be stated that in the presence of comparable daily exposure levels (around $260 \mu \mathrm{g} / \mathrm{day} / \mathrm{kg}$ of body weight) the incidence of unequivocal indications of toxicity, viz. protein oxidation, was higher for $\mathrm{Hg}(\mathrm{II})$. Moreover, if the degree of exposure is considered as the resulting internal exposure (i.e., tHg concentration in the brain), the higher neurotoxic potential of $\mathrm{Hg}$ (II) in comparison with $\mathrm{MeHg}$ is even more clear, since a lower $\mathrm{Hg}$ accumulation was observed for $\mathrm{Hg}(\mathrm{II})$ as compared to $\mathrm{MeHg}$ (e.g. 5 times lower at E14).

\section{Conclusions}

According to the present results, it can be concluded that:

1. Dietary MeHg exposure promoted a higher accumulation of $\mathrm{Hg}$ (2to 6-fold) in the brain of $D$. sargus when compared to $\mathrm{Hg}$ (II) exposure. Dietary MeHg was likely more efficiently transported into the brain of fish than waterborne $\mathrm{Hg}(\mathrm{II})$.

2. Both $\mathrm{Hg}$ forms followed an identical accumulation in the brain over time, showing a significant increase after 3 days of exposure. $\mathrm{Hg}$ (II) was not significantly eliminated from the brain during 28 days of depuration, while MeHg levels in the brain were significantly reduced.

3. Though sharing the same toxic moiety, $\mathrm{Hg}$ (II) and $\mathrm{MeHg}$ showed to trigger different protective processes and exert toxicity in the brain through different pathways. $\mathrm{Hg}$ (II) led to oxidative damage (as protein oxidation) without a proportional and efficient activation of the antioxidant system, while $\mathrm{MeHg}$ increased antioxidant protection in a way that prevented oxidative damage in the brain in the 
majority of time-points. Brain proteins seemed to be more susceptible to $\mathrm{Hg}$ (II) toxicity than lipids.

4. Waterborne $\mathrm{Hg}$ (II) displayed a higher neurotoxic potential as compared to dietary $\mathrm{MeHg}$, according to the brain oxidative status. In order to prevent an underestimation of risk for wild fish populations, both $\mathrm{Hg}$ forms need to be considered in the design of environmental health assessment plans.

\section{Acknowledgements}

Patrícia Pereira benefited from post-doctoral grant (SFRH/BPD/ 107718/2015) supported by "Fundação para a Ciência e a Tecnologia" (FCT). This work has been supported by the Research project financed by FCT PTDC/AAG-REC/2488/2012 (NEUTOXMER - Neurotoxicity of mercury in fish and association with morphofunctional brain alterations and behavior shifts), as well as by the Centre for Environmental and Marine Studies (CESAM). Authors are also grateful to Joana Raimundo, Olinda Araújo and Marisa Barata for their support in the laboratory work, as well as to the "Aquaculture Research Station of IPMA" for hosting the experiments.

\section{References}

Almroth, B.C., Sturve, J., Berglund, Å., Förlin, L., 2005. Oxidative damage in eelpout (Zoarces viviparus), measured as protein carbonyls and TBARS, as biomarkers. Aquat. Toxicol. 73, 171-180.

Andres, S., Laporte, J.-M., Mason, R.P., 2002. Mercury accumulation and flux across the gills and the intestine of the blue crab (Callinectessapidus). Aquat. Toxicol. 56, 303-320.

Aschner, J., Aschner, M., 2007. Methylmercury neurotoxicity: exploring potential novel targets. Open Toxicology Journal 1, 1-10.

Baker, M.A., Cerniglia, G.J., Zaman, A., 1990. Microtiter plate assay for the measurement of glutathione and glutathione disulfide in large numbers of biological samples. Anal. Biochem. 190, 360-365.

Berntssen, M.H.G., Aatland, A., Handy, R.D., 2003. Chronic dietary mercury exposure causes oxidative stress, brain lesions, and altered behaviour in Atlantic salmon (Salmo salar) parr. Aquat. Toxicol. 65, 55-72.

Bird, R.P., Draper, H.H., 1984. Comparative Studies on Different Methods of Malonaldehyde Determination Methods in Enzymology. Academic Presspp. 299-305.

Ceccatelli, S., Daré, E., Moors, M., 2010. Methylmercury-induced neurotoxicity and apoptosis. Chem. Biol. Interact. 188, 301-308.

Chen, J.-H., Singh, N., Tay, H., Walczyk, T., 2014. Imbalance of iron influx and efflux causes brain iron accumulation over time in the healthy adult rat. Metallomics 6, $1417-1426$

Choi, B.H., Yee, S., Robles, M., 1996. The effects of glutathione glycoside in methyl mercury poisoning. Toxicol. Appl. Pharmacol. 141, 357-364.

Claiborne, A., 1985. Catalase Activity. CRC Handbook of Methods for Oxygen Radical Research 1. pp. 283-284.

Clarkson, T.W., Magos, L., 2006. The toxicology of mercury and its chemical compounds. Crit. Rev. Toxicol. 36, 609-662.

Clarkson, T.W., Vyas, J.B., Ballatori, N., 2007. Mechanisms of mercury disposition in the body. Am. J. Ind. Med. 50, 757-764.

Costley, C.T., Mossop, K.F., Dean, J.R., Garden, L.M., Marshall, J., Carrol, J., 2000. Determination of mercury in environmental and biological samples using pyrolysis atomic absorption spectrometry with gold amalgamation. Anal. Chim. Acta 405, 179-183.

Cribb, A.E., Leeder, J.S., Spielberg, S.P., 1989. Use of a microplate reader in an assay of glutathione reductase using 5,5'-dithiobis(2-nitrobenzoic acid). Anal. Biochem. 183, 195-196.

Crump, K.L., Trudeau, V.L., 2009. Mercury-induced reproductive impairment in fish. Environ. Toxicol. Chem. 28, 895-907.

De Flora, S., Bennicelli, C., Bagnasco, M., 1994. Genotoxicity of mercury compounds. A review. Mutation Research/Reviews in Genetic Toxicology 317, 57-79.

Dringen, R., Pawlowski, P.G., Hirrlinger, J., 2005. Peroxide detoxification by brain cells. J. Neurosci. Res. 79, 157-165.

Dutczak, W.J., Ballatori, N., 1994. Transport of the glutathione-methylmercury complex across liver canalicular membranes on reduced glutathione carriers. J. Biol. Chem. 269, 9746-9751.

El-Demerdash, F., 2001. Effects of selenium and mercury on the enzymatic activities and lipid peroxidation in brain, liver, and blood of rats. J. Environ. Sci. Health B 36, 489-499.

EPA, 1998. Method 7473 (SW-846): Mercury in Solids and Solutions by Thermal Decomposition, Amalgamation, and Atomic Absorption Spectrophotometry.

Ercal, N., Gurer-Orhan, H., Aykin-Burns, N., 2001. Toxic metals and oxidative stress part I: mechanisms involved in metal-induced oxidative damage. Curr. Top. Med. Chem. 1, 529-539.

Evans, R.D., Hickie, B., Rouvinen-Watt, K., Wang, W., 2016. Partitioning and kinetics of methylmercury among organs in captive mink (Neovison vison): a stable isotope tracer study. Environ. Toxicol. Pharmacol. 42, 163-169.
Farina, M., Aschner, M., Rocha, J.B., 2012. Redox State in Mediating Methylmercury Neurotoxicity Methylmercury and Neurotoxicity. Springerpp. 101-125.

Farina, M., Avila, D.S., da Rocha, J.B.T., Aschner, M., 2013. Metals, oxidative stress and neurodegeneration: a focus on iron, manganese and mercury. Neurochem. Int. 62, 575-594.

Filho, D.W., Tribess, T., Gáspari, C., Claudio, F.D., Torres, M.A., Magalhães, A.R.M., 2001 Seasonal changes in antioxidant defenses of the digestive gland of the brown mussel (Perna perna). Aquaculture 203, 149-158.

Flohé, L., Günzler, W.A., 1984. Assays of glutathione peroxidase. Methods Enzymol. 105, $114-120$.

Franco, J.L., Posser, T., Dunkley, P.R., Dickson, P.W., Mattos, J.J., Martins, R., Bainy, A.C.D., Marques, M.R., Dafre, A.L., Farina, M., 2009. Methylmercury neurotoxicity is associated with inhibition of the antioxidant enzyme glutathione peroxidase. Free Radic. Biol. Med. 47, 449-457.

Gentès, S., Maury-Brachet, R., Feng, C., Pedrero, Z., Tessier, E., Legeay, A., MesmerDudons, N., Baudrimont, M., Maurice, L., Amouroux, D., Gonzalez, P., 2015. Specific effects of dietary methylmercury and inorganic mercury in zebrafish (Danio rerio) determined by genetic, histological, and metallothionein responses. Environ. Sci. Technol. 49, 14560-14569.

Giri, U., Iqbal, M., Athar, M., 1996. Porphyrin-mediated photosensitization has a weak tumor promoting activity in mouse skin: possible role of in situ-generated reactive oxygen species. Carcinogenesis 17, 2023-2028.

Glaser, V., Nazari, E.M., Müller, Y.M.R., Feksa, L., Wannmacher, C.M.D., Rocha, J.B.T., Bem, A.F.D., Farina, M., Latini, A., 2010. Effects of inorganic selenium administration in methylmercury-induced neurotoxicity in mouse cerebral cortex. Int. J. Dev. Neurosci. 28, 631-637.

Glynn, A.W., Norrgren, L., Müssener, Å., 1994. Differences in uptake of inorganic mercury and cadmium in the gills of the zebrafish, Brachydanio rerio. Aquat. Toxicol. 30, $13-26$.

Gornall, A.G., Bardawill, C.J., David, M.M., 1949. Determination of serum proteins by means of the biuret reaction. J. Biol. Chem. 177, 751-766.

Grune, T., 2000. Oxidative stress, aging and the proteasomal system. Biogerontology 1, $31-40$.

Guilherme, S., Válega, M., Pereira, M.E., Santos, M.A., Pacheco, M., 2008a. Antioxidant and biotransformation responses in Liza aurata under environmental mercury exposure - relationship with mercury accumulation and implications for public health. Mar. Pollut. Bull. 56, 845-859.

Guilherme, S., Válega, M., Pereira, M.E., Santos, M.A., Pacheco, M., 2008b. Erythrocytic nuclear abnormalities in wild and caged fish (Liza aurata) along an environmental mercury contamination gradient. Ecotoxicol. Environ. Saf. 70, 411-421.

Habig, W.H., Pabst, M.J., Jakoby, W.B., 1974. Glutathione S-transferases: the first enzymatic step in mercapturic acid formation. J. Biol. Chem. 249, 7130-7139.

Horvat, M., Nolde, N., Fajon, V., Jereb, V., Logar, M., Lojen, S., Jacimovic, R., Falnoga, I., Liya, Q., Faganeli, J., Drobne, D., 2003. Total mercury, methylmercury and selenium in mercury polluted areas in the province Guizhou, China. Sci. Total Environ. 304, 231-256.

Hussain, S., Atkinson, A., Thompson, S., Khan, A., 1999. Accumulation of mercury and its effect on antioxidant enzymes in brain, liver, and kidneys of mice. J. Environ. Sci. Health B 34, 645-660.

Hussain, S., Rodgers, D., Duhart, H., Ali, S., 1997. Mercuric chloride-induced reactive oxygen species and its effect on antioxidant enzymes in different regions of rat brain. J. Environ. Sci. Health B 32, 395-409.

Kerper, L.E., Mokrzan, E.M., Clarkson, T.W., Ballatori, N., 1996. Methylmercury efflux from brain capillary endothelial cells is modulated by intracellular glutathione but not ATP. Toxicol. Appl. Pharmacol. 141, 526-531.

Klinck, J., Dunbar, M., Brown, S., Nichols, J., Winter, A., Hughes, C., Playle, R. C., 2005 Influence of water chemistry and natural organic matter on active and passive uptake of inorganic mercury by gills of rainbow trout (Oncorhynchus mykiss). Aquat. Toxicol. $72,161-175$.

Korbas, M., MacDonald, T.C., Pickering, I.J., George, G.N., Krone, P.H., 2012. Chemical form matters: differential accumulation of mercury following inorganic and organic mercury exposures in zebrafish larvae. ACS Chem. Biol. 7, 411-420.

Korbas, M., O'Donoghue, J.L., Watson, G.E., Pickering, I.J., Singh, S.P., Myers, G.J., Clarkson, T.W., George, G.N., 2010. The chemical nature of mercury in human brain following poisoning or environmental exposure. ACS Chem. Neurosci. 1, 810-818.

Leaner, J.J., Mason, R.P., 2002. Methylmercury accumulation and fluxes across the intestine of channel catfish, Ictalurus punctatus. Comparative Biochemistry and Physiology Part C: Toxicology \& Pharmacology 132, 247-259.

Li, C., Zhao, Z., Lei, B., An, J., Zhang, X., Yu, Y., 2015. Polybrominated diphenyl ethers in the air and comparison of the daily intake and uptake through inhalation by Shanghai residents with those through other matrices and routes. Environ. Sci. Pollut. Res. 22, 1750-1759.

Li, P., Feng, X.B., Qiu, G.L., Shang, L.H., Li, Z.G., 2009. Mercury pollution in Asia: a review of the contaminated sites. J. Hazard. Mater. 168, 591-601.

Locarnini, S.J.P., Presley, B.J., 1996. Mercury concentrations in benthic organisms from a contaminated estuary. Mar. Environ. Res. 41, 225-239.

MacDonald, T.C., Korbas, M., James, A.K., Sylvain, N.J., Hackett, M.J., Nehzati, S., Krone, P.H., George, G.N., Pickering, I.J., 2015. Interaction of mercury and selenium in the larval stage zebrafish vertebrate model. Metallomics 7, 1247-1255.

Mason, R.P., Reinfelder, J.R., Morel, F.M.M., 1996. Uptake, toxicity, and trophic transfer of mercury in a coastal diatom. Environ. Sci. Technol. 30, 1835-1845.

Mieiro, C., Pereira, M., Duarte, A., Pacheco, M., 2011. Brain as a critical target of mercury in environmentally exposed fish (Dicentrarchus labrax) - bioaccumulation and oxidative stress profiles. Aquat. Toxicol. 103, 233-240.

Monnet-Tschudi, F., Zurich, M.-G., Honegger, P., 1996. Comparison of the developmental effects of two mercury compounds on glial cells and neurons in aggregate cultures of 
rat telencephalon. Brain Res. 741, 52-59.

Mori, N., Yasutake, A., Hirayama, K., 2007. Comparative study of activities in reactive oxygen species production/defense system in mitochondria of rat brain and liver, and their susceptibility to methylmercury toxicity. Arch. Toxicol. 81, 769-776.

Oliveira Ribeiro, C.A., Pelletier, E., Pfeiffer, W.C., Rouleau, C., 2000. Comparative uptake, bioaccumulation, and gill damages of inorganic mercury in tropical and nordic freshwater fish. Environ. Res. 83, 286-292.

Pereira, P., Puga, S., Cardoso, V., Pinto-Ribeiro, F., Raimundo, J., Barata, M., PousãoFerreira, P., Pacheco, M., Almeida, A., 2016. Inorganic mercury accumulation in brain following waterborne exposure elicits a deficit on the number of brain cells and impairs swimming behavior in fish (white seabream-Diplodus sargus). Aquat. Toxicol. 170, 400-412.

Pereira, P., Raimundo, J., Araújo, O., Canário, J., Almeida, A., Pacheco, M., 2014. Fish eyes and brain as primary targets for mercury accumulation - a new insight on environmental risk assessment. Sci. Total Environ. 494-495, 290-298.

Pereira, P., Raimundo, J., Barata, M., Araujo, O., Pousao-Ferreira, P., Canario, J., Almeida, A., Pacheco, M., 2015. A new page on the road book of inorganic mercury in fish body - tissue distribution and elimination following waterborne exposure and post-exposure periods. Metallomics 7, 525-535.

Pickhardt, P.C., Stepanova, M., Fisher, N.S., 2006. Contrasting uptake routes and tissue distributions of inorganic and methylmercury in mosquitofish (Gambusia affinis) and redear sunfish (Lepomis microlophus). Environ. Toxicol. Chem. 25, 2132-2142.

Puga, S., Pereira, P., Pinto-Ribeiro, F., O'Driscoll, N.J., Mann, E., Barata, M., PousãoFerreira, P., Canário, J., Almeida, A., Pacheco, M., 2016. Unveiling the neurotoxicity of methylmercury in fish (Diplodus sargus) through a regional morphometric analysis of brain and swimming behavior assessment. Aquat. Toxicol. 180, 320-333.

Regoli, F., Gorbi, S., Frenzilli, G., Nigro, M., Corsi, I., Focardi, S., Winston, G., 2002. Oxidative stress in ecotoxicology: from the analysis of individual antioxidants to a more integrated approach. Mar. Environ. Res. 54, 419-423.

Roos, D.H., Puntel, R.L., Santos, M.M., Souza, D.O.G., Farina, M., Nogueira, C.W., Aschner, M., Burger, M.E., Barbosa, N.B.V., Rocha, J.B.T., 2009. Guanosine and synthetic organoselenium compounds modulate methylmercury-induced oxidative stress in rat brain cortical slices: involvement of oxidative stress and glutamatergic system. Toxicol. in Vitro 23, 302-307.
Rouleau, C., Borg-Neczak, K., Gottofrey, J., Tjälve, H., 1999. Accumulation of waterborne mercury (II) in specific areas of fish brain. Environ. Sci. Technol. 33, 3384-3389.

Shacter, E., Williams, J.A., Lim, M., Levine, R.L., 1994. Differential susceptibility of plasma proteins to oxidative modification: examination by western blot immunoassay. Free Radic. Biol. Med. 17, 429-437.

Smith, C.D., Carney, J.M., Tatsumo, T., Stadtman, E.R., Floyd, R.A., Markesbery, W.R., 1992. Protein oxidation in aging brain. Ann. N. Y. Acad. Sci. 663, 110-119.

Stringari, J., Nunes, A.K., Franco, J.L., Bohrer, D., Garcia, S.C., Dafre, A.L., Milatovic, D., Souza, D.O., Rocha, J.B., Aschner, M., 2008. Prenatal methylmercury exposure hampers glutathione antioxidant system ontogenesis and causes long-lasting oxidative stress in the mouse brain. Toxicol. Appl. Pharmacol. 227, 147-154.

Vandeputte, C., Guizon, I., Genestie-Denis, I., Vannier, B., Lorenzon, G., 1994. A microtiter plate assay for total glutathione and glutathione disulfide contents in cultured/ isolated cells: performance study of a new miniaturized protocol. Cell Biol. Toxicol. $10,415-421$.

Wang, R., Wong, M.-H., Wang, W.-X., 2010. Mercury exposure in the freshwater tilapia Oreochromis niloticus. Environ. Pollut. 158, 2694-2701.

Wang, W.-X., Wong, R.S., 2003. Bioaccumulation kinetics and exposure pathways of inorganic mercury and methylmercury in a marine fish, the sweetlips Plectorhinchus gibbosus. Mar. Ecol. Prog. Ser. 261, 257-268.

Wang, Y., Wang, D., Lin, L., Wang, M., 2015. Quantitative proteomic analysis reveals proteins involved in the neurotoxicity of marine medaka Oryzias melastigma chronically exposed to inorganic mercury. Chemosphere 119, 1126-1133.

West, S.G., Finch, J.F., Curran, P.J., 1995. Structural Equation Models with Nonnormal Variables Structural Equation Modeling: Concepts, Issues, and Applications. pp. 56-75.

WHO, 1991. Inorganic Mercury. World Health Organization.

Yee, S., Choi, B.H., 1996. Oxidative stress in neurotoxic effects of methylmercury poisoning. Neurotoxicology 17, 17-26.

Zemolin, A., Meinerz, D., de Paula, M., Mariano, D., Rocha, J., Pereira, A., Posser, T., Franco, J., 2012. Evidences for a role of glutathione peroxidase 4 (GPx4) in methylmercury induced neurotoxicity in vivo. Toxicology 302, 60-67.

Zheng, W., Aschner, M., Ghersi-Egea, J.-F., 2003. Brain barrier systems: a new frontier in metal neurotoxicological research. Toxicol. Appl. Pharmacol. 192, 1-11. 